\title{
Thermal and Physical Characterization of PEG Phase Change Materials Enhanced by Carbon-Based Nanoparticles
}

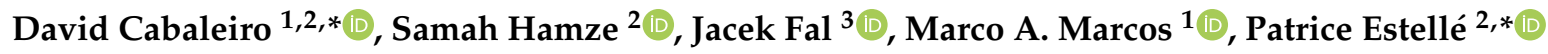 \\ and Gaweł Żyła ${ }^{3, *}$ \\ 1 Departamento de Física Aplicada, Facultade de Ciencias, Universidade de Vigo, 36310 Vigo, Spain; \\ mmarcosm@uvigo.es \\ 2 Laboratoire de Génie Civil et Génie Mécanique, LGCGM, Université Rennes, 35000 Rennes, France; \\ samah.hamze@univ-rennes1.fr \\ 3 Department of Experimental Physics, Rzeszow University of Technology, 35-959 Rzeszow, Poland; \\ jacekfal@prz.edu.pl \\ * Correspondence: dacabaleiro@uvigo.es (D.C.); patrice.estelle@univ-rennes1.fr (P.E.); \\ gzyla@prz.edu.pl (G.Z.); Tel.: +48-17-865-1273 (G.Z.)
}

Received: 29 April 2020; Accepted: 8 June 2020; Published: 15 June 2020

\begin{abstract}
This paper presents the preparation and thermal/physical characterization of phase change materials (PCMs) based on poly(ethylene glycol) $400 \mathrm{~g} \cdot \mathrm{mol}^{-1}$ and nano-enhanced by either carbon black $(\mathrm{CB})$, a raw graphite/diamond nanomixture $(\mathrm{G} / \mathrm{D}-\mathrm{r})$, a purified graphite/diamond nanomixture (G/D-p) or nano-Diamond nanopowders with purity grades of $87 \%$ or $97 \%$ (nD87 and nD97, respectively). Differential scanning calorimetry and oscillatory rheology experiments were used to provide an insight into the thermal and mechanical changes taking place during solid-liquid phase transitions of the carbon-based suspensions. PEG400-based samples loaded with $1.0 \mathrm{wt} . \%$ of raw graphite/diamond nanomixture (G/D-r) exhibited the lowest sub-cooling effect (with a reduction of $\sim 2 \mathrm{~K}$ regarding neat PEG400). The influences that the type of carbon-based nanoadditive and nanoparticle loading ( 0.50 and $1.0 \mathrm{wt} . \%)$ have on dynamic viscosity, thermal conductivity, density and surface tension were also investigated in the temperature range from 288 to $318 \mathrm{~K}$. Non-linear rheological experiments showed that all dispersions exhibited a non-Newtonian pseudo-plastic behavior, which was more noticeable in the case of carbon black nanofluids at low shear rates. The highest enhancements in thermal conductivity were observed for graphite/diamond nanomixtures $(3.3-3.6 \%)$, while nano-diamond suspensions showed the largest modifications in density $(0.64-0.66 \%)$. Reductions in surface tension were measured for the two nano-diamond nanopowders (nD87 and nD97), while slight increases (within experimental uncertainties) were observed for dispersions prepared using the other three carbon-based nanopowders. Finally, a good agreement was observed between the experimental surface tension measurements performed using a Du Noüy ring tensiometer and a drop-shape analyzer.
\end{abstract}

Keywords: NePCM; PEG400; carbon black; graphite; nano-diamond; solid-liquid phase change; thermal conductivity; surface tension; dynamic viscosity; density

\section{Introduction}

Energy consumption is increasing rapidly to meet the requirements of the growing world population and rising demand from industrialized countries [1,2]. This fact, together with the intensive use of energy sources from fossil fuels, has triggered several environmental issues [3,4]. Since this situation is expected to become much worse in the coming years, a large-scale transformation of 
current worldwide energy policies towards sustainability is essential [5]. Thermal energy storage, TES, can substantially contribute to such a transition towards a green energy system. Thus, by stocking thermal energy when available so that it can be released for utilization when necessary, it is possible to address the mismatches between demand and supply when recovering waste heat or harvesting renewable energy sources [6].

Materials can accumulate thermal energy in three main different ways: sensible heat (by using a temperature difference), latent heat (when undergoing a change in phase), and thermo-chemical (during a reversible reaction by breaking and forming molecular bonds) storage [7]. Latent TES technologies based on phase change materials, PCMs, exhibit large store capacities in a temperature range near to their phase change (charging and discharging processes present a nearly isothermal nature). Among different phase transitions, solid-liquid and solid-solid are particularly attractive since they provide high energy storage densities, something that, in turn, reduces the technological requirements of TES systems [8]. PCMs have been widely used in latent heat accumulation to improve the energy management in heat pumps [9,10], automotive [11], solar engineering [12,13], spacecraft [14,15] or heating, ventilation, and air conditioning facilities [16-19], for instance.

Over the last decades several materials have been proposed as PCMs and classified according to their temperature range of interest $[8,11,20]$. Polymeric compounds such as poly(ethylene glycol)s, PEGs, are very promising candidates owing to their relatively high latent heats, chemical/thermal stabilities, non-corrosiveness and suitable transition temperatures, which can be tuned by means of the polymer molecular mass [21-23]. In particular, the PEG400 used as base material in our investigation has a melting point of $~ 277-281 \mathrm{~K}$, which is attractive for cold thermal storage [24]. However, as with many other organic materials, PEGs have rather low thermal conductivities (in the range of $\left.0.2-0.3 \mathrm{~W} \cdot \mathrm{m}^{-1} \cdot \mathrm{K}^{-1}[11,25,26]\right)$, which slow the thermal charging/discharging of accumulated heat and may hinder broad-scale practical utilization [27].

Traditional attempts to intensify the heat transfer performance in TES tanks mainly consisted of extending the heat exchange surface used to charge or discharge the stored energy $[19,28,29]$. A revision of previous investigations shows finned surfaces [30-34], multi-tubular systems [35] or lessing rings [36] with different configurations were used to achieve a more rapid response and efficient thermal management of stored heat. When it comes to poly(ethylene glycol)-based systems, Baygi et al. [34] investigated the thermal management of photovoltaic solar cells integrated with PEG1000 and extended fins. The results showed that, by embedding the PCM with fins, the efficiency of the system to convert solar energy into electricity enhanced by $8 \%$. Similar investigations were recently conducted by Firoozzadeh et al. [31,32] using PEG600 as phase change material. In these last cases, a PCM-fin combination was also proven effective to control the temperature, and efficiency of electricity production enhanced by $2-3 \%$.

Encapsulating the PCMs within a polymeric/inorganic/metallic shell [37-39] or impregnating them into fiber matrixes [40], porous materials [41,42] or foams [43,44] are other research techniques for heat transfer enhancement [45]. In particular, porous supports have sparked enormous interest because of their large, specific surface areas, high volume porosity and excellent temperature stability [46]. Although porous materials such as zeolites, diatom earth, gamma alumina or expanded perlite have also been considered as subtracts [47], most scientific effort regarding poly(ethylene glycol)s has been addressed to the development of supports based on silica, $\mathrm{SiO}_{2}$, [48-51] or carbon structures [52-55]. Thus, Feng et al. [53] prepared PEG100-based composites using active carbon and silica molecular sieves. Among the investigated form-stabilized PCMs, PEG/AC combinations containing $80 \mathrm{wt}$ \% of poly(ethylene glycol) exhibited the largest latent heat, the least super-cooling and the better heat storage efficiency. Wang et al. [54] developed active carbon and mesoporous carbon supports (with different pore structures) to stabilize PEG6000 and observed that the hexagonal pore structure promoted the filling and impregnation of the mesoporous support with PEG molecules. More recently, Chen et al. [55] embedded PEG8000 in a highly graphitized 3D network to shape-stabilize the PCM and achieve superior thermal energy harvesting. Such nano-composites could be potentially attractive in electronics 
systems such as computers to buffer excessive rises in temperature. A thorough control of support porosity is a key issue to avoid a considerable reduction in the space to be occupied by the PCM, which may reduce the total energy storage density. Additionally, as reported by Feng et al. [53] and Wang et al. [46], a tiny porous size can lead to very low enthalpy (or even zero) due to the strong confinement effect on the mobility of PEG molecules.

Although effective at promoting heat transfer, the use of an ample quantity of fins/fillers/fibers usually undermines energy storage density and increases the cost of the storage systems [56]. For that reason, in those applications in which leakage is not a major concern and a shape stabilization or encapsulation can be avoided, heat transfer performance can be also enhanced by dispersing highly-conductive nano-sized particles [57]. This especial kind of latent media, also known as nano-enhanced phase change materials (NePCMs) or nano-PCMs [58-60], stems from the progresses made over the last decades in the development of the advanced heat transfer fluids called nanofluids [61]. Metal oxide [62-64], metallic [65-69] and carbon-based nanomaterials [70-75] have been used as thermal conductivity enhancers to improve the thermal conductivity of poly(ethylene glycols). In addition to improving the effective thermal conductivity of PCMs, the dispersion of nanoparticles has a second advantage: it promotes nucleation during solidification/recrystallization [76]. A better nucleation rate reduces the difference in temperature between melting and solidifying transitions (sub-cooling effect), and consequently, the temperature range the material needs to cover to reversely undergo solid-liquid phase change is also shorter [77].

$\mathrm{He}$ et al. [75] prepared graphene nanoplatelets/PEG4000 nano-composites with various contents of graphene and studied the improvements in the thermal and photo-thermal performance of the new NePCMs in comparison with the neat poly(ethylene glycol). A thermal conductivity enhancement of up to $146 \%$ and a reduction of only $6.3 \%$ in latent heat were obtained for a $2 \%$ mass concentration of graphene nanoplatelets, while photo-thermal conversion results indicated that the designed nano-composites were very promising for the application in solar energy conversion and storage. Wang et al. [72] prepared nano-enhanced phase change materials as dispersions of sodium dodecyl sulfate (SDS) functionalized multiwall carbon nanotubes (MWCNTs) in PEG8000 with various nanoparticle loadings (0.5-5 wt.\%). Melting temperature and latent heat slightly decreased from 337 to $335 \mathrm{~K}$ and from 165 to $150 \mathrm{J.g}^{-1}$ as MWCNT content increased from 0.5 to $5 \%$ in mass, respectively. Conversely, thermal conductivity rose with nanoparticle loading from 0.295 to $0.531 \mathrm{~W} \cdot \mathrm{m}^{-1} \cdot \mathrm{K}^{-1}$.

Ranjbar et al. [78] investigated the stability and thermal conductivity of phase change materials based on either commercial paraffin wax, stearic acid or polyethylene glycol (with a melting point $\sim 331-336 \mathrm{~K}$ ) and containing either pristine or functionalized multi-walled carbon nanotubes. Stability results showed that functionalized MWCNT or SDBS-assisted MWCNT suspensions had higher stability in PEG8000 than pristine MWCNTs, while thermal conductivity measurements revealed that in liquid phase the addition of $1 \mathrm{wt} . \%$ of nanoparticles enhanced this property by $16.6 \%$ in comparison to neat PEG8000. Marcos et al. $[67,71,73]$ prepared and characterized NePCMs based on poly(ethylene glycol) 400 and containing functionalized graphene nanoplatelets [73], multi-walled carbon nanotubes [71] or silver nanoparticles [67]. These energy storage media, envisaged for low-temperature applications, reached enhancements in thermal conductivity ranging from 3.9\% (for the silver dispersion at $1.1 \mathrm{wt} . \%$ loading [67]) to $23 \%$ (in the case of the functionalized graphene at $0.5 \mathrm{wt} . \%$ [73]), while the sub-cooling effect reduced by $7.1 \%$ in the case of the silver/PEG400 sample with $1.1 \%$ of nanoparticles [67].

In addition to a high latent heat at a phase change temperature suitable for the intended use of the TES system and an appropriate thermal conductivity that ensures a rapid exchange of stored energy, other thermophysical properties such as dynamic viscosity, surface tension or volumetric behavior are also important. Thus, for example, reliable information regarding dynamic viscosity is necessary to estimate the pressure drop and pumping power in those cases in which work in the liquid phase requires a pumping system [56,77]. Likewise, surface tension is related to the crystallization ability of materials, whereas volumetric properties are required to determine volume changes during phase change or due to the effect of temperature $[79,80]$. Additionally, an accurate characterization of these 
physical and thermal properties is also necessary to describe melt convection heat transfer response by means of different non-dimensional ratios such as Nusselt, Rayleigh, Stefan, or Fourier numbers.

Marcos et al. [71] studied the flow behavior of PEG400-based dispersions loaded with 0.01-1.0 wt.\% of multi-walled carbon nanotubes and observed that, except for $0.01 \%$ dispersion that was Newtonian, all NePCMs exhibited a shear-thinning behavior. Yapici et al. [62] studied the rheological behavior of $\mathrm{TiO}_{2}$ dispersions in PEG200 containing nanoparticle concentrations in the range 1-10 wt.\%. Non-linear viscoelastic tests revealed a non-Newtonian pseudo-plastic behavior for $\mathrm{TiO}_{2}$ contents larger than $1 \%$, while oscillatory analyses evidenced that highly loaded samples showed a gel-like structure. Zafarani-Moattar and Majdan-Cegincara [64] investigated the volumetric and (magneto)rheological properties for PEG400-based dispersions of $\mathrm{Fe}_{3} \mathrm{O}_{4}$ nanoparticles either bared or coated with oleic acid. In the studied range of volumetric concentrations, from $0.48-3.6 \%$, samples showed a pseudo-plastic flow behavior. Additionally, obtained results from excess molar volume and isentropic compressibility analyses evidenced that oleic acid covalently binds to the surface of iron oxide nanoparticles. Qi et al. [23] designed PEG1000-based phase change materials shape-stabilized with graphene oxide and doped with graphene nanoplatelets as thermal enhancers. The authors completed their thermal study of the designed composites with an analysis of the mechanical properties during the phase change throughout oscillatory rheological tests.

In this study, different NePCMs were designed as dispersions of carbon black (CB), a raw graphite/diamond nanomixture (G/D-r), a purified graphite/diamond nanomixture (G/D-p) or a nano-Diamond nanopowder with purity grades of either $87 \%$ (nD87) or 97\% (nD97) in poly(ethylene glycol) $400 \mathrm{~g} \cdot \mathrm{mol}^{-1}$ at two different nanoparticle loadings (0.5 and $1.0 \mathrm{wt} \%$ ). Various experimental techniques were carried out to investigate the thermal and physical properties of those materials. Solid-liquid phase transitions were determined by means of differential scanning calorimetry and oscillatory rheological experiments. In the temperature range from 288 to $318 \mathrm{~K}$ (in which PEG400 is in liquid phase), thermal conductivity was investigated using a transient hot wire instrument, surface tension was obtained using two experimental devices (a Du Noüy ring tensiometer and a drop-shape analyzer), dynamic viscosity was determined using a rotational rheometer, and the volumetric analyses were performed on a U-tube densimeter.

\section{Materials and Methods}

\subsection{Materials and Nanofluid Preparation}

Five different carbon-based nanomaterials, all them supplied by PlasmaChem GmbH (Berlin, Germany), were used as nanoadditives, viz., carbon black, CB; nano-diamonds purified with grade G, nD87; nano-diamonds purified with grade G01, nD97; a purified graphite/diamond nanomixture, G/D-p; and a raw graphite/diamond nanomixture, G/D-r. The average sizes and purities declared by the manufacturer are listed in Table 1.

Table 1. Studied carbon nanopowders ${ }^{\dagger}$.

\begin{tabular}{|c|c|c|c|c|c|}
\hline $\begin{array}{l}\text { Label in the } \\
\text { Article }\end{array}$ & Nanopowder Description & $\begin{array}{c}\text { Average } \\
\text { Particle Size } \\
(\mathrm{nm})\end{array}$ & $\begin{array}{c}\text { Diamond } \\
\text { Content }\end{array}$ & $\begin{array}{l}\text { Non-Diamond } \\
\text { Carbon } \\
\text { Content }\end{array}$ & Ash Content \\
\hline $\mathrm{CB}$ & carbon black & 13 & - & - & $<0.02$ wt. $\%$ \\
\hline nD87 & nano-diamonds, purified, grade $G$ & 4 & $>87$ wt. $\%$ & $<5-7$ wt. $\%$ & $<6$ wt. $\%$ \\
\hline nD97 & nano-diamonds, purified, grade G01 & 4 & $>97$ wt. $\%$ & $<0.7$ wt. $\%$ & $<1.4$ wt. $\%$ \\
\hline G/D-p & graphite/diamond nanomixture, purified & 4 & $>20$ wt. $\%$ & - & $<0.3$ wt. $\%$ \\
\hline G/D-r & graphite/diamond nanomixture, raw & 4 & $>20$ wt. $\%$ & - & $<6$ wt. $\%$ \\
\hline
\end{tabular}

Thorough size and morphological analyses of batches of these same five commercial nanopowders were recently carried out by Vallejo et al. [81]. According to the transmission electron microscopy (TEM) studies reported, nD87 and nD97 powders contain quasi-spherical nanoparticles with average sizes close in value to $\sim 4 \mathrm{~nm}$, indicated by the supplier. In addition, nearly spherical nanoparticles 
were observed in TEM micrographs of G/D-p and G/D-r nanoparticles. In G/D-p and G/D-r, it was also possible to distinguish two nanoparticle size populations: the tiniest ones corresponded to nano-diamonds, while the others (with slightly larger size and more frequently present) were graphite nanoparticles. Finally, TEM images of CB nanopowders showed nanoparticles with irregular shape and sizes of $\sim 10-15 \mathrm{~nm}$.

In this study, nanoparticle densities of $1.9,3.1,3.2,2.52$ and $2.54 \mathrm{~g} / \mathrm{cm}^{-3}$ were considered for carbon back (CB) [82], nano-diamonds purified with grade $\mathrm{G}$ (nD87), nano-diamonds purified with grade G01 (nD97), purified graphite/diamond nanomixture, (G/D-p) [83] and raw graphite/diamond nanomixture (G/D-r) [83], respectively. The densities for the two nano-diamond mixtures were calculated as the weight average value between the densities of graphite $\left(2.26 \mathrm{~g} / \mathrm{cm}^{-3}\right.$ [82]) and nano-diamonds $\left(3.2 \mathrm{~g} \cdot \mathrm{cm}^{-3}\right.$ [84]), considering the amount of nano-diamonds (87 and $97 \%$ in mass) and impurities (all assumed with the same density as graphite)

The material used as base fluid was a poly(ethylene glycol) with a declared molecular mass of $\sim 400 \mathrm{~g} \cdot \mathrm{mol}^{-1}$. As for the nanoparticles, the base fluid was used as supplied, without any further chemical purification or treatment. A high-resolution APEX Qe FT-ICR (Bruker Daltonics, Billerica, MA, USA) mass spectrometer based on electrospray ionization (ESI) was utilized to confirm the purity and molecular mass of the PEG400. Figure 1 shows a representative ESI mass spectrum obtained in positive ion mode.

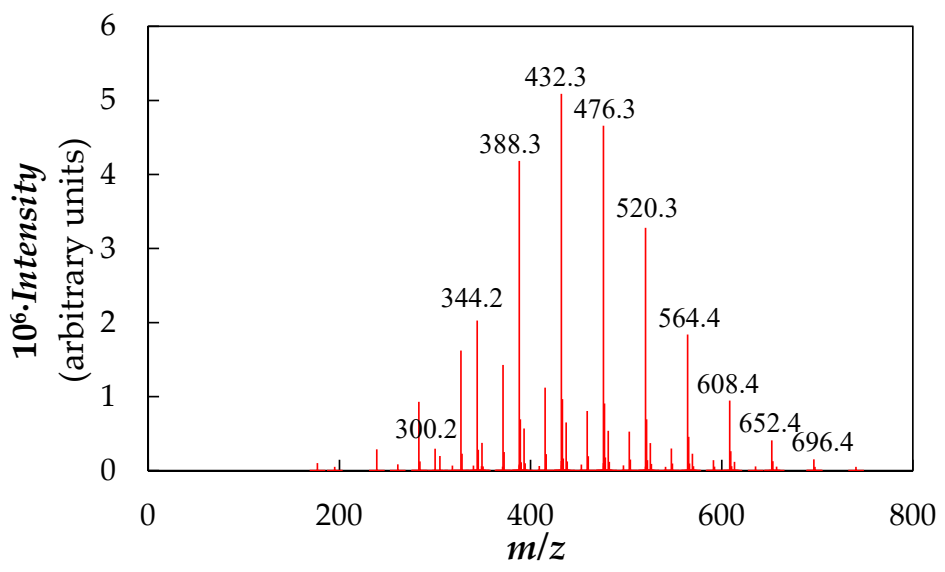

Figure 1. Positive ion electrospray ionization (ESI) mass spectra of neat PEG400.

Studied polymer molecules have an expected structure like $\mathrm{HO}-\left[\mathrm{CH}_{2}-\mathrm{CH}_{2}-\mathrm{O}\right]_{n}-\mathrm{H}$. Hence, all detected peaks in the mass spectrum can be attributed to poly(ethylene glycol) molecules mainly cationized with $\mathrm{H}^{+}, \mathrm{NH}_{4}{ }^{+}, 2 \mathrm{H}^{+}, \mathrm{Na}^{+}$or $\mathrm{K}^{+}$with $n=4-14$. The sample exhibits a uniform molecular mass with an average number of $M_{n}=424.5 \mathrm{~g} \cdot \mathrm{mol}^{-1}$, an average value of $M_{w}=443.1 \mathrm{~g} \cdot \mathrm{mol}^{-1}$ and a polydispersity index of $M_{w} / M_{n}=1.044$. These values are closer in size to those reported by Marcos et al. $[67,71,73]$ for other commercial PEG400.

Five different nanofluid sets, viz., CB/PEG400, nD87/PEG400, nD97/PEG400, G/D-p/PEG400 and G/D-r/PEG400, were prepared at 0.5 and $1.0 \%$ nanoparticle mass concentrations via a two-step method. Thus, the required amounts of nanopowder and base fluid necessary to obtain the predefined concentrations were weighted on an analytical balance Radwag AS 220/X (Radwag, Radom, Poland) with an accuracy of $1 \times 10^{-4} \mathrm{~g}$. After mechanically shaking the mixtures using a Genius 3 (IKA, Staufen, Germany) vortex system for $30 \mathrm{~min}$, samples were sonicated for $200 \mathrm{~min}$ in an Emmi $60 \mathrm{HC}$ ultrasound wave bath (EMAG, Moerfelden-Walldorf, Germany) working with a ultrasound power of $450 \mathrm{~W}$ and a frequency of $45 \mathrm{kHz}$ [81]. Special care was taken to periodically replace the water of the ultrasonic bath and avoid sample overheating during sonication process. 


\subsection{Thermal and Physical Characterization}

Melting and crystallization processes were characterized in terms of temperature and enthalpy by means of a Q2000 (TA Instruments, New Castle, WA, USA) differential scanning calorimetry, DSC, equipped with a refrigerated cooling system RSC90. Scans were performed in the temperature range from 223.15 to $313.15 \mathrm{~K}$ under nitrogen atmosphere (mole fraction purity higher than 0.99999 ) using $\sim 10 \mu \mathrm{g}$ of sample hermetically encapsulated in $20 \mu \mathrm{L} \mathrm{T}_{\text {zero }}{ }^{\mathrm{TM}}$ aluminium pans. Before experiments, studied materials were held at a temperature of $313 \mathrm{~K}$ (more than $20 \mathrm{~K}$ above their melting transition) to erase the prior thermal history of the materials, and the first freeze-thaw cycle was disregarded. Estimated uncertainties are $0.3 \mathrm{~K}$ (with a repeatability of $0.1 \mathrm{~K}$ ) for transition temperatures and $1.2 \mathrm{~J} \cdot \mathrm{g}^{-1}$ (with a repeatability of $0.7 \mathrm{~J} \cdot \mathrm{g}^{-1}$ ) for latent heats [85].

Rheological studies were carried out on a Malvern Kinexus Pro (Malvern Instruments Ltd., Worcestershire, UK) stress-controlled rheometer [86]. Temperature was established and controlled to within $\pm 0.2 \mathrm{~K}$ using a Peltier system placed below the lower plate. Three different types of tests were carried out. First, the shear rate dependence of dynamic viscosity (also referred as flow curve) was studied at 4 isotherms in the range from 288.15 to $318.15 \mathrm{~K}$ (within which the PEG400 is in liquid phase) by means of non-linear viscoelastic tests. For such analyses, a cone-plate geometry with a rotating cone $60 \mathrm{~mm}$ in diameter, cone angle of $1^{\circ}$ and truncation of $30 \mu \mathrm{m}$ was coupled to the rheometer. Viscosity, $\eta$, values were collected in steady-state conditions at shear stresses logarithmically increasing from 0.8 to $200 \mathrm{~Pa}$ with at least 10 points per decimal. The experimental uncertainty of viscosity measurements using this experimental device is $4 \%$ [86]. Then, oscillatory strain sweeps were performed at 253.15 and $263.15 \mathrm{~K}$ (at which the PEG400 used as base fluid is in solid phase) as well as at 283.15 and $293.15 \mathrm{~K}$ (PEG400 is in liquid phase) in order to partially define the linear viscoelastic region. In such rheological oscillatory experiments the frequency was fixed at $1 \mathrm{~Hz}$, while the strain amplitude was progressively increased up to $\sim 0.1 \%$ when NePCMs were in solid phase ( 253.15 and $263.15 \mathrm{~K}$ ) and up to $\sim 1 \%$ when liquid ( 283.15 and $293.15 \mathrm{~K}$ ). Finally, temperature sweeps were performed in the range between 253.15 and $293.15 \mathrm{~K}$ in cooling and heating mode using a constant scanning rate of $0.5 \mathrm{~K} \cdot \mathrm{min}^{-1}$ to ensure uniform temperature conditions throughout the sample. In these last assays, frequency was fixed at $1 \mathrm{~Hz}$ and strain was kept as low as $0.05 \%$ to guarantee linear viscoelastic behavior of the materials in the whole analyzed temperature range. Strain and temperature sweeps were performed using a plate-plate geometry of $40 \mathrm{~mm}$ in diameter and a constant gap of $1 \mathrm{~mm}$, and sandpaper was glued to the upper plate to prevent slippage [87].

Thermal conductivity, $k$, was studied in the temperature range from 288.15 to $318.15 \mathrm{~K}$ (PEG400 is in liquid phase) by means of a THW-L2 thermal conductivity meter (Thermtest Inc., Fredericton, NB, Canada). This device is based on the transient short hot wire (THW) technique and allows direct $k$ determinations of liquids in accordance with the ASTM D7896-14 standard test method [88]. The alumel wire used as probe has a length of $60 \mathrm{~mm}$ and a diameter of $\sim 0.1 \mathrm{~mm}$. The probe is vertically immersed in the sample, which completely surrounds the sensor, so that heat can freely diffuse in all directions. Both probe and sample are contained in a proper vessel, which is placed in a thermostatic bath to ensure uniform initial temperature. A low thermal power, $80 \mathrm{~mW}$, and a short power input time, $1.5 \mathrm{~s}$, were selected to avoid natural convection phenomena. The accuracy in thermal conductivity determinations with this device declared by the manufacturer is $5 \%$. However, previous tests with water and ethylene glycol [89,90] show average deviations with literature [91] better than $3 \%$. More details about this device and the followed experimental method can be found in a recent work by Banisharif et al. [89].

Densities, $\rho$, of neat PEG400 and carbon-based suspensions were experimentally determined at atmospheric pressure and in the temperature range from 288.15 to $313.15 \mathrm{~K}$ by means of a DMA 500 (Anton Paar, Graz, Autria) vibrating tube densimeter. Measurements with this device show an uncertainty of $\pm 0.02 \mathrm{~K}$ in temperature and $\pm 0.0005 \mathrm{~g} \cdot \mathrm{cm}^{-3}$ in density [92].

Following a previous investigation on ethylene glycol-based nanofluids prepared using various types of nitride nanoparticles recently published by Wanic et al. [93], two different methods were 
considered in the present work to determine the surface tension at the sample fluid/air interface, $\sigma$ or SFT. A comparison of the results produced using the two methods will provide information on the consistency of the two techniques to study the surface tension of nanostructured samples. First, this property was studied for the neat PEG400 and nanofluids in the temperature range from 288 to 318 K by means of a DSA-30 (KRÜSS GmBH, Hamburg, Germany) drop-shape analyzer based on the pendant drop technique [94]. Sample temperature was controlled within $\pm 0.1 \mathrm{~K}$ using a TC40 environmental chamber (also from Krüss $\mathrm{GmbH}$ ). A needle with an outside diameter of 15 gauge $(1.83 \mathrm{~mm})$ was used to create drops with a volume of $\sim 15-16 \mu \mathrm{L}$. The experimental uncertainty of measurements performed with the drop-shape analyzer was estimated to be less than $1 \%$ [95]. Surface tension measurements were also performed at 298 and $308 \mathrm{~K}$ for the base fluid and the highest concentration of each carbon nanofluid set using a PI-MT1A.KOM (Polon-Izot, Warsaw, Poland) surface tensiometer based on the Du Noüy ring method. In this case, determinations were performed using a ring with a radius of $9.691 \mathrm{~mm}$ and made of a platinum-iridium wire (0.203 $\mathrm{mm}$ in radius). Previous surface tension studies performed for substances of well-known SFT with this same Du Noüy tensiometer showed deviations within 1\% [93]. Further details about the principles of both techniques and the followed experimental procedures can be found in Wanic et al. [93].

\section{Results and Discussion}

\subsection{Solid-Liquid Phase Change}

\subsubsection{Differential Scanning Calorimetry Studies}

The thermal profiles of solid-liquid transitions were studied in the temperature range from 223.15 to $313.15 \mathrm{~K}$ using DSC at scan rates of $0.5 \mathrm{~K} \cdot \mathrm{min}^{-1}$.

Figure 2 shows the cooling and heating thermograms for neat PEG400 and the five dispersions prepared at the highest nanoparticle concentration $(1.0 \mathrm{wt} . \%)$, while melting temperatures, crystallizing temperatures and melting enthalpies are presented in Table 2. Melting latent heats of neat PEG400 in the range from 105.3 to $117.3 \mathrm{~J} \cdot \mathrm{g}^{-1}$ are usually reported for poly(ethylene glycols) with similar molecular masses [11,73]. As can be observed, the addition of any of the five carbon nanostructures leads to shifts in melting and crystallizing transitions towards lower temperatures. This behavior was previously attributed in the literature $[73,96]$ to the fact that the presence of the nanostructures reduces the mobility of poly(ethylene glycol) segments during solid-liquid change. As a consequence of the reduced ability of the polymer chains to bend/fold, PEG crystals formed during solidification are less thick and those thinner PEG crystals exhibit solid-liquid transitions at lower temperatures [97]. In addition, it is also possible to appreciate a reduction in the undesirable sub-cooling effect from $4.0 \mathrm{~K}$ (neat-PEG400) to $2.3 \mathrm{~K}$ (carbon black, CB, dispersion at $1.0 \mathrm{wt} . \%$ ) or $2.0 \mathrm{~K}$ (raw graphite/diamond nanomixture, G/D-r, suspension at $1.0 \mathrm{wt} . \%)$. This is due to the improvement in the nucleation during crystallizing, as a consequence of the additional nucleation sites provided by dispersed nanostructures [76]. In addition, enthalpy of fusion decreases with the nanoparticle loading, with reductions ranging from $2.4 \%$ (nano-Diamonds purified with grade G01, nD97) to 6.9\% (raw graphite/diamond nanomixture, G/D-r, suspension at $1.0 \mathrm{wt} . \%)$. These diminutions in the latent heat capacity can be attributed to a lower crystallinity degree of the polymer due to the presence of the nanomaterials. The crystallinity degree of a polymer, $X_{c}$, can be quantified by means of the following expression [97]:

$$
X_{\mathrm{c}}=100 \cdot \frac{\Delta h_{\text {melt. }}}{\Delta h_{\text {melt. }}^{0}}
$$

where $\Delta h_{\text {melt. }}$ is the latent heat of fusion experimentally measured for the studied poly(ethylene glycol), while $\Delta h_{\text {melt. }}^{0}$ is the latent heat corresponding to a polymer with $100 \%$ crystallinity. In this case a value of $\Delta h_{\text {melt. }}^{0}=196.8 \mathrm{~J} \cdot \mathrm{g}^{-1}$ was considered, as reported by Pielichowski et al. [97]. As presented in Table 2, studied neat poly(ethylene glycol) exhibits $X_{c}=54.3 \%$, which reduces down to a value of $50.5 \%$ in the 
case of G/D-r(1 wt.\%)/PEG400 NePCM. Crystallinity degrees here obtained for neat PEG400 by using Equation (1) are in the range from 53.5 to $59.7 \%$, which could be calculated from the heats of fusions reported in the literature [11,73] for poly(ethylene glycol)s with similar molecular masses.
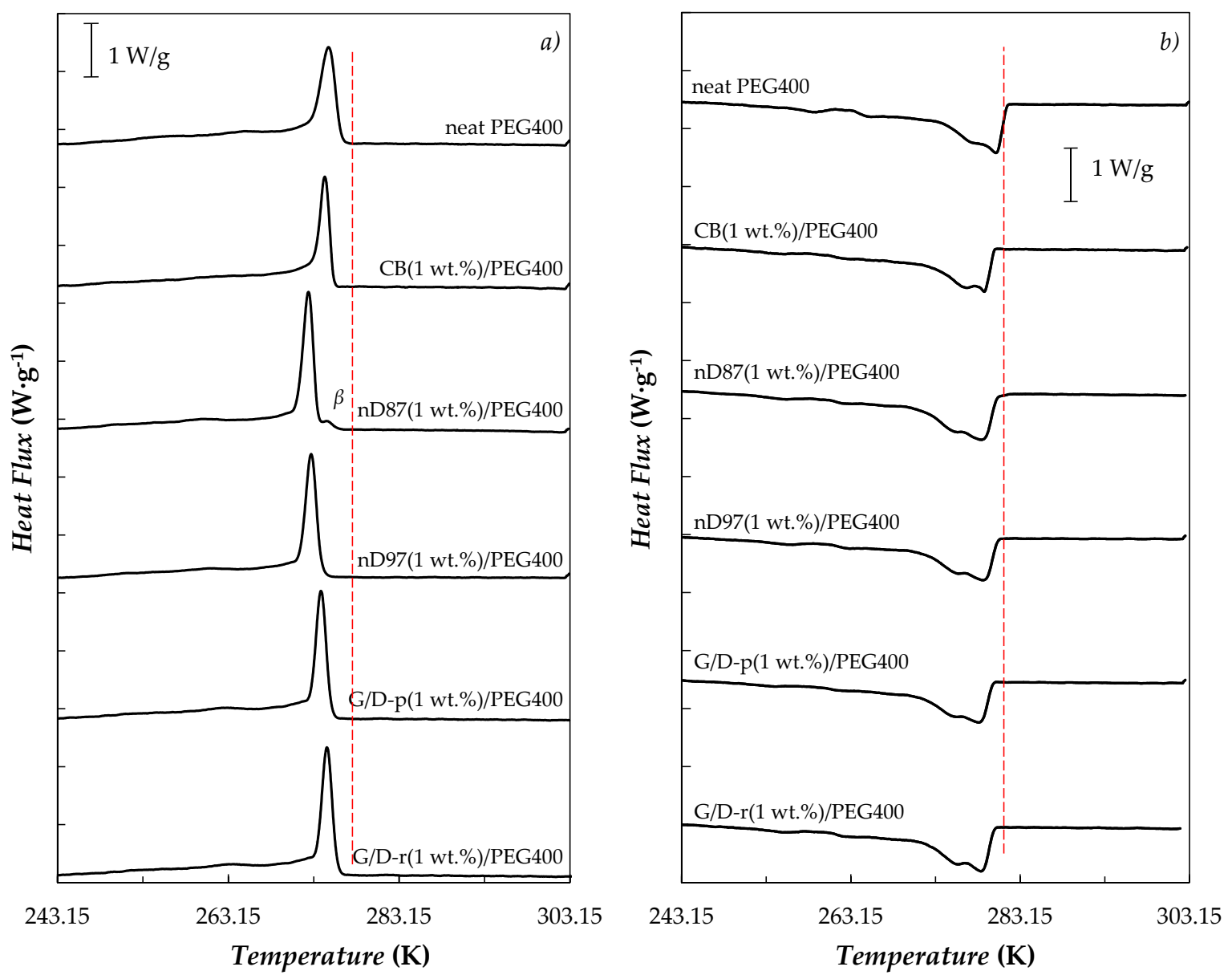

Figure 2. (a) Cooling and (b) heating differential scanning calorimetry (DSC) curves obtained at $0.5 \mathrm{~K} \cdot \mathrm{min}^{-1}$ for the neat PEG400 and the nanofluids prepared at $1 \mathrm{wt} . \%$ nanoparticle loadings.

Table 2. Crystallizing, $T_{\text {cryst., }}$ and melting, $T_{\text {melt., }}$ temperatures; latent heat of fusion, $\Delta H_{\text {melt. }}$ and crystallinity degrees, $X_{c}$, obtained for neat PEG400 and dispersions prepared at $1 \mathrm{wt} . \%$ nanoparticle concentrations from DSC scans at $0.5 \mathrm{~K} \cdot \mathrm{min}^{-1}$.

\begin{tabular}{ccccc}
\hline Sample & $\boldsymbol{T}_{\text {cryst. }}(\mathbf{K})$ & $\boldsymbol{T}_{\text {melt. }}(\mathbf{K})$ & $\Delta \boldsymbol{H}_{\text {melt. }}\left(\mathbf{J} \cdot \mathbf{g}^{\mathbf{- 1}}\right)$ & $\boldsymbol{X}_{\mathbf{c}}$ \\
\hline neat PEG400 & 276.2 & 280.2 & 106.8 & 54.3 \\
CB(1 wt.\%)/PEG400 & 276.0 & 278.2 & 101.2 & 51.4 \\
nD87(1 wt.\%)/PEG400 & $275.9(\beta), 273.8$ & 278.0 & 99.6 & 50.6 \\
nD97(1 wt.\%)/PEG400 & 274.3 & 278.5 & 104.2 & 52.9 \\
G/D-p(1 wt.\%)/PEG400 & 275.4 & 278.0 & 100.3 & 51.0 \\
G/D-r(1 wt.\%)/PEG400 & 276.0 & 278.0 & 99.4 & 50.5 \\
\hline
\end{tabular}

\subsubsection{Dynamic Oscillatory Rheological Analyses}

Phase changes or internal structural readjustments in polymers are directly related to variations in their viscoelastic properties. Hence, dynamic rheological experiments were also used in order to obtain an alternative insight into the solid-liquid phase transitions of neat PEG400 and the carbon-based suspensions prepared at the highest nanoparticle content (1.0 wt.\%). Similar studies have been 
performed for other novel materials based on poly(ethylene glycol) [98,99], alkanes/paraffins [98,100] or ionic liquids [101].

In order to partially define the linear viscoelastic region (LVR), strain sweeps were first performed at four temperatures: at 253.15 and $263.15 \mathrm{~K}$ (at which the PEG400 used as base fluid is in solid phase) as well as at 283.15 and $293.15 \mathrm{~K}$ (PEG400 is in liquid phase). As an example, Figure 3 shows the stain sweeps obtained at an angular frequency of $1 \mathrm{~Hz}$ for neat PEG400 and three representative dispersions (1 wt.\% concentrations of either CB, nD87 or G/D-p).

\begin{tabular}{cccc}
\hline$\bigcirc$ & Storage Modulus, $G^{\prime},(T=253.15 \mathrm{~K})$ & $\square$ & Storage Modulus, $G^{\prime},(T=283.15 \mathrm{~K})$ \\
$\bigcirc$ & Loss Modulus, $G^{\prime \prime},(T=253.15 \mathrm{~K})$ & $\square$ & Loss Modulus, $G^{\prime \prime},(T=283.15 \mathrm{~K})$ \\
$\triangle$ & Storage Modulus, $G^{\prime},(T=263.15 \mathrm{~K})$ & $\diamond$ & Storage Modulus, $G^{\prime},(T=293.15 \mathrm{~K})$ \\
$\Delta$ & Loss Modulus, $G^{\prime \prime},(T=263.15 \mathrm{~K})$ & $\diamond$ & Loss Modulus, $G^{\prime \prime},(T=293.15 \mathrm{~K})$ \\
\hline
\end{tabular}
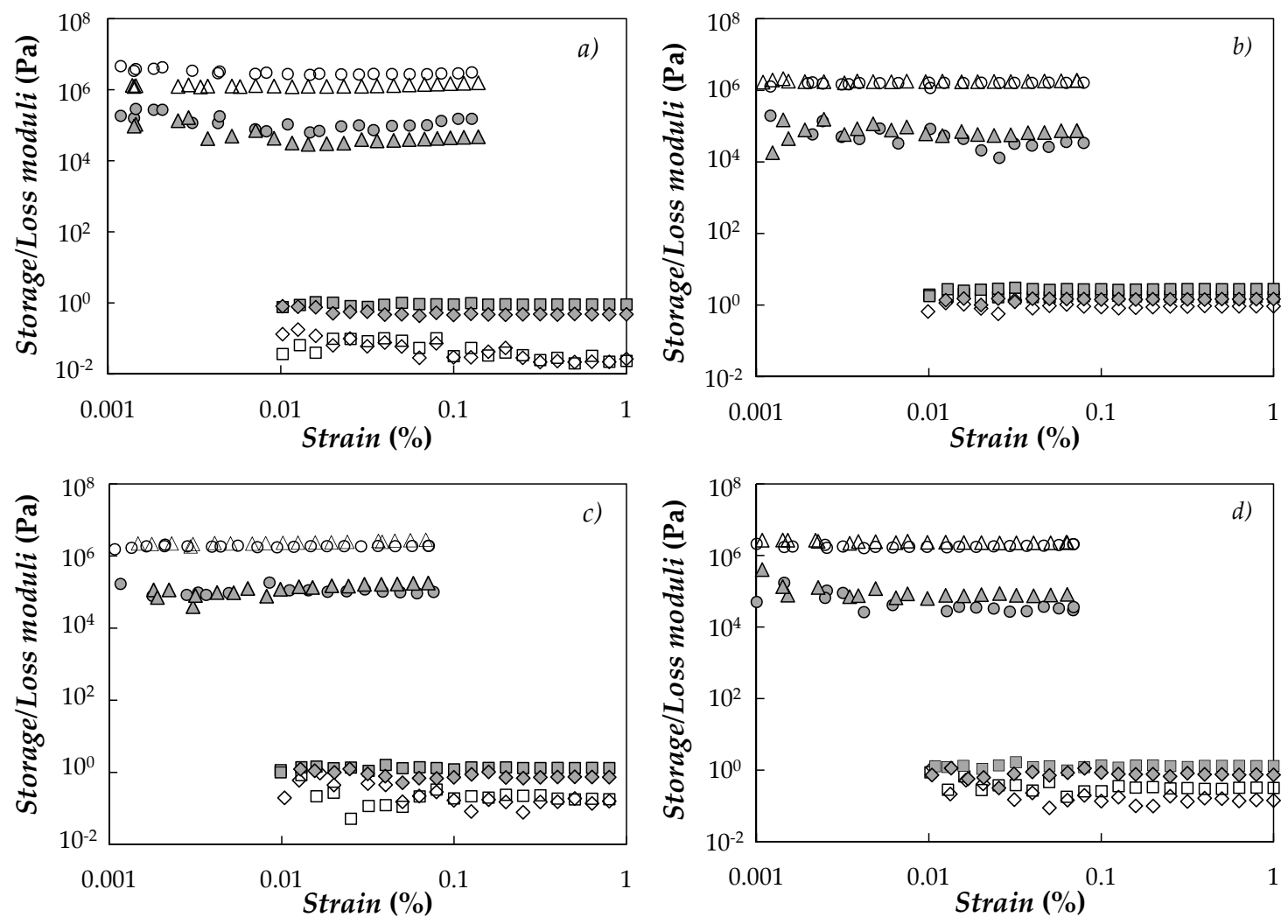

Figure 3. Storage and loss moduli as a function of strain obtained for (a) neat PEG400 as well as (b) CB (1 wt.\%)/PEG400, (c) nD87 (1 wt.\%)/PEG400 and (d) G/D-p (1 wt.\%)/PEG400 nanofluids. Oscillatory frequency was kept constant at $1 \mathrm{~Hz}$.

As can be observed, in solid phase (see 253.15 and $263.15 \mathrm{~K}$ isotherms) dynamics storage, $G^{\prime}$, and loss moduli, $G^{\prime \prime}$, remain nearly constant below oscillatory strains close to $1 \%$. At those temperatures, $G^{\prime}>G^{\prime \prime}$ (at least one order of magnitude), evidencing the solid-like behavior of the samples. At 283.15 and $293.15 \mathrm{~K}$ isotherms, storage and loss moduli were almost constant for oscillatory strains larger than $0.01 \%$ (lower strains were not considered to avoid possible detection issues when working in liquid phase) while $G^{\prime \prime}>G^{\prime}$, which indicates that the base fluid and nanofluids present a liquid-like behavior at those temperatures.

Then, the solid-liquid phase behavior was investigated throughout temperature sweeps in the range between 253.15 and $293.15 \mathrm{~K}$, at constant cooling/heating rates of $0.5 \mathrm{~K} \cdot \mathrm{min}^{-1}$ (the same temperature scan conditions as those used in DSC analyses) and an oscillatory frequency of $1 \mathrm{~Hz}$. In such experiments, oscillatory strain was set to $0.5 \%$ with the aim of ensuring that: (i) the experimental device was working in the region of optimal operating conditions and (ii) the material was being 
investigated within the linear viscoelastic range (LVR). Figure 4 shows the dynamic mechanical spectra (storage modulus, $G^{\prime}$, loss modulus, $G^{\prime \prime}$, and damping factor, $\operatorname{tang} \delta$ ) as a function of temperature obtained for the neat PEG400 and three representative suspensions prepared at $1 \mathrm{wt} . \%$.

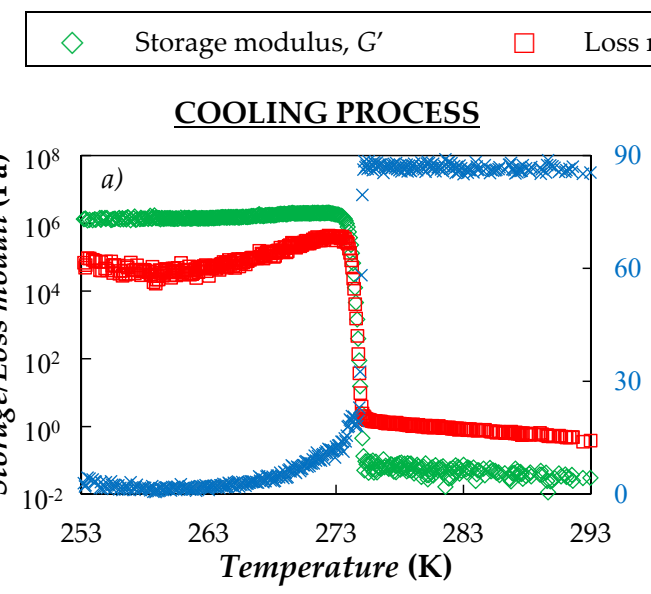

Phase angle, $\tan \delta \delta$
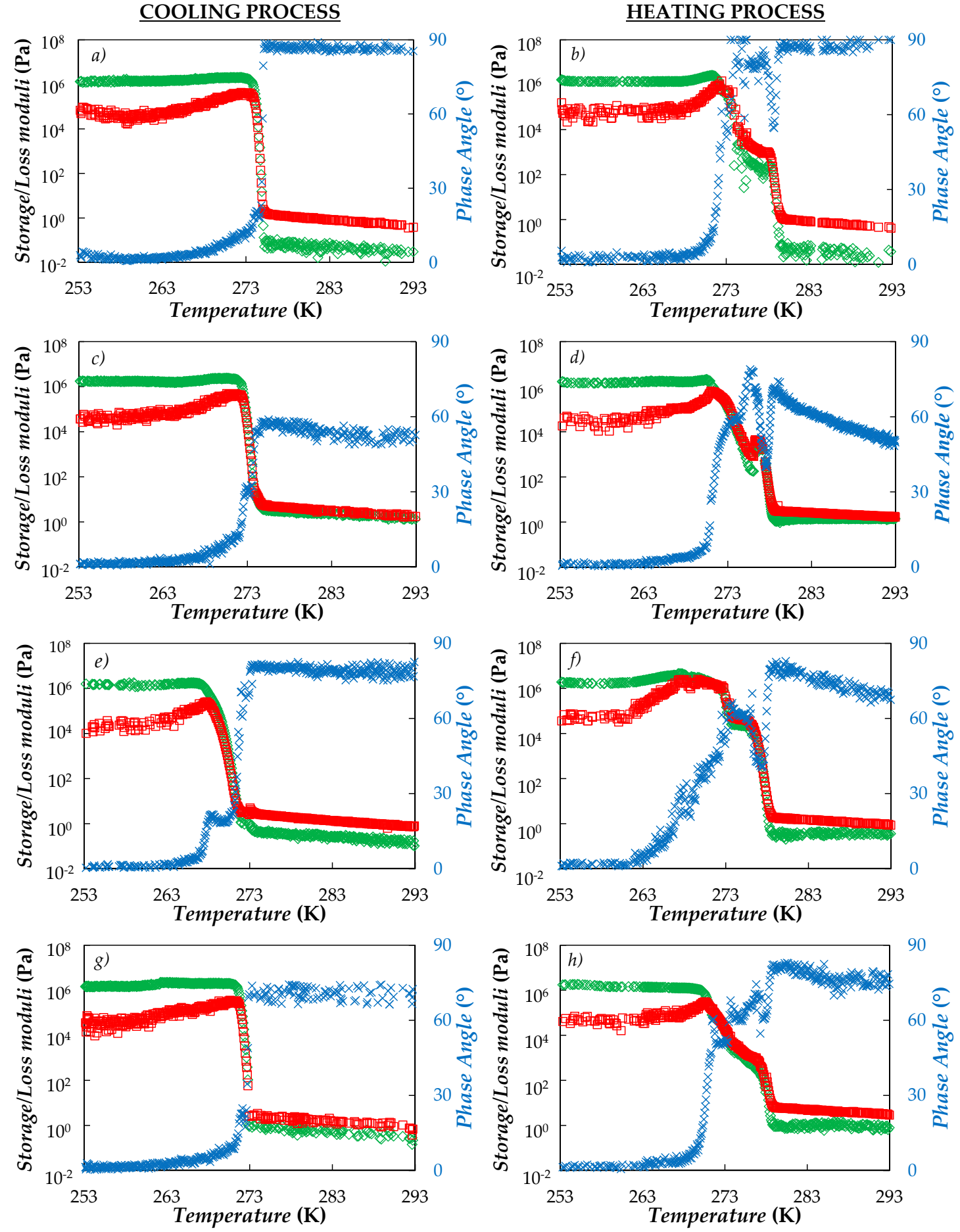

Figure 4. Temperature evolution of $(\diamond)$ storage modulus, $(\square)$ loss modulus and $(\times)$ loss phase angle obtained during $(\mathbf{a}, \mathbf{c}, \mathbf{e}, \mathbf{g})$ cooling and $(\mathbf{b}, \mathbf{d}, \mathbf{f}, \mathbf{h})$ heating processes at $0.5 \mathrm{~K} \cdot \mathrm{min}^{-1}$ for $(\mathbf{a}, \mathbf{b})$ neat PEG400, (c,d) CB(1 wt.\%)/PEG400, (e,f) nD87(1 wt.\%)/PEG400 and (g,h) G/D-p(1 wt.\%)/PEG400. Test strain and frequency were kept constant at $0.05 \%$ and $1 \mathrm{~Hz}$, respectively. 
In the cooling process of neat PEG400, at high temperatures the storage modulus is very low $\left(G^{\prime}<0.1 \mathrm{~Pa}\right)$ and at least one order of magnitude inferior to the loss modulus. When the temperature reaches $\sim 275.8 \mathrm{~K}$ (close to the crystallizing point, $T_{\text {cryst }}=276.2 \mathrm{~K}$, determined from DSC analyses) the storage modulus shows a sharp increase, while the damping factor sharply decreases from $86^{\circ}$ to less than $10^{\circ}$ (the crossover between $G^{\prime}$ and $G^{\prime \prime}$, which indicates the beginning of the crystalline network formation, occurs at tang $\delta=45^{\circ}$ ). As for the nanofluids, similar $G^{\prime}$ and $G^{\prime \prime}$ evolutions were observed during the cooling processes. It must be pointed out that, even though nanofluids continue having a liquid-like appearance (in all cases $\operatorname{tang} \delta>45^{\circ}$ ) at temperatures at which the base fluid is supposed to be liquid, the addition of nanoparticles led to an increase in the storage modulus. This increase in the elastic behavior is usually observed when rigid elements are suspended in their network [102,103].

Heating curves show that the transition from solid to liquid-like phase occurs in a broader temperature range than crystallization. This is consistent with the DSC thermograms in which thermal events due to melting are prolonged from 263 to $280 \mathrm{~K}$ (Figure 2b). Additionally, in heating scans it is also possible to observe something similar to a plateau in $G^{\prime}$ and $G^{\prime \prime}$. Such behavior was also reported in the literature for other materials based on poly(ethylene glycol)s or paraffin and agrees with the two superimposed peaks also observed in heating DSC thermograms (Figure 2b).

\subsection{Dynamic Viscosity}

The effect of particle loading on the shear rate-shear viscosity profile was studied for the neat PEG400 and the five carbon nanofluid sets by means of non-linear viscoelastic measurements. Figure 5 shows the steady shear viscosity curves obtained at the four studied temperatures. Dynamic viscosity results obtained for base PEG400 exhibit an absolute average deviation of $2.9 \%$ with the values reported by Marcos et al. [73] for a poly(ethylene glycol) with a similar molecular mass.

Unlike PEG400, the studied suspensions evidence a non-Newtonian behavior with a shear-thinning viscosity (i.e., dynamic viscosity reduces as shear rate increases), which gets stronger with the increasing nanoparticle content. Pseudo-plastic viscosity curves were also reported by Marcos et al. [71] when they studied the flow behavior of PEG400-based dispersions loaded with $0.05-1.0 \mathrm{wt}$.\% of multi-walled carbon nanotubes. Żyła et al. [83,92] comprehensively investigated the rheological behavior of ethylene glycol dispersions containing nano-diamond mixtures (nD87 and nD97 [92]) as well as graphite/diamond mixtures (G/D-p and G/D-r [83]), analyzing the effect that nano-diamond purity and ash content have on shear rate-shear viscosity curves, among other thermophysical properties. Recently, Vallejo et al. [81] performed a complete rheological study of the dispersions of the same carbon-based nanomaterials used in the present study but based on ethylene glycol (EG). Vallejo et al. [81] reported a shear-thinning behavior for suspensions of these five carbon nanopowders (CB, nD87, nD97, G/D-p or G/D-r) in the nanoparticle concentration range from 0.25 to $2.0 \%$.

The non-Newtonian behavior of carbon-based PCMs can be described using the Ostwald-de Waele (power law) model, expressed as

$$
\eta=K \cdot \dot{\gamma}^{n-1}
$$

where $K$ and $n$ fitting parameters are the flow consistency factor and the flow behavior index, respectively. Power law parameters obtained from the viscosity flow curves of the different studied suspensions at shear rates up to $100 \mathrm{~s}^{-1}$ are gathered in Table 3. A good description of the non-Newtonian region was observed for all studied dispersions, with absolute average deviations in dynamic viscosity equal to or lower than $4.2 \%$. A comparison between the different studied nanofluid sets shows a much stronger shear-thinning degree in the case of carbon black (CB) dispersions, followed by nano-diamond sets (nD87 and nD97) and finally graphite/diamond nanomixtures (G/D-p and G/D-r). Thus, a minimum flow consistency index of $n=0.77$ was observed at $318.15 \mathrm{~K}$ for the CB/PEG400 sample loaded with $1.0 \mathrm{wt} . \%$, while the $n$ value ranged from 0.87 to 0.99 for PEG400 dispersions prepared using the other carbon powders. When compared with EG dispersions prepared at equivalent concentrations of the same carbon-based nanopowders [81], PEG400 suspensions show a less strong pseudoplastic behavior. 
However, in both base fluids (EG [81] and PEG400), it is possible to observe that the dispersions of nano-diamonds (nD87 and nD97) and graphite/diamond nanomixtures (G/D-p and G/D-r) show a slightly stronger shear-thinning effect as the temperature increases.
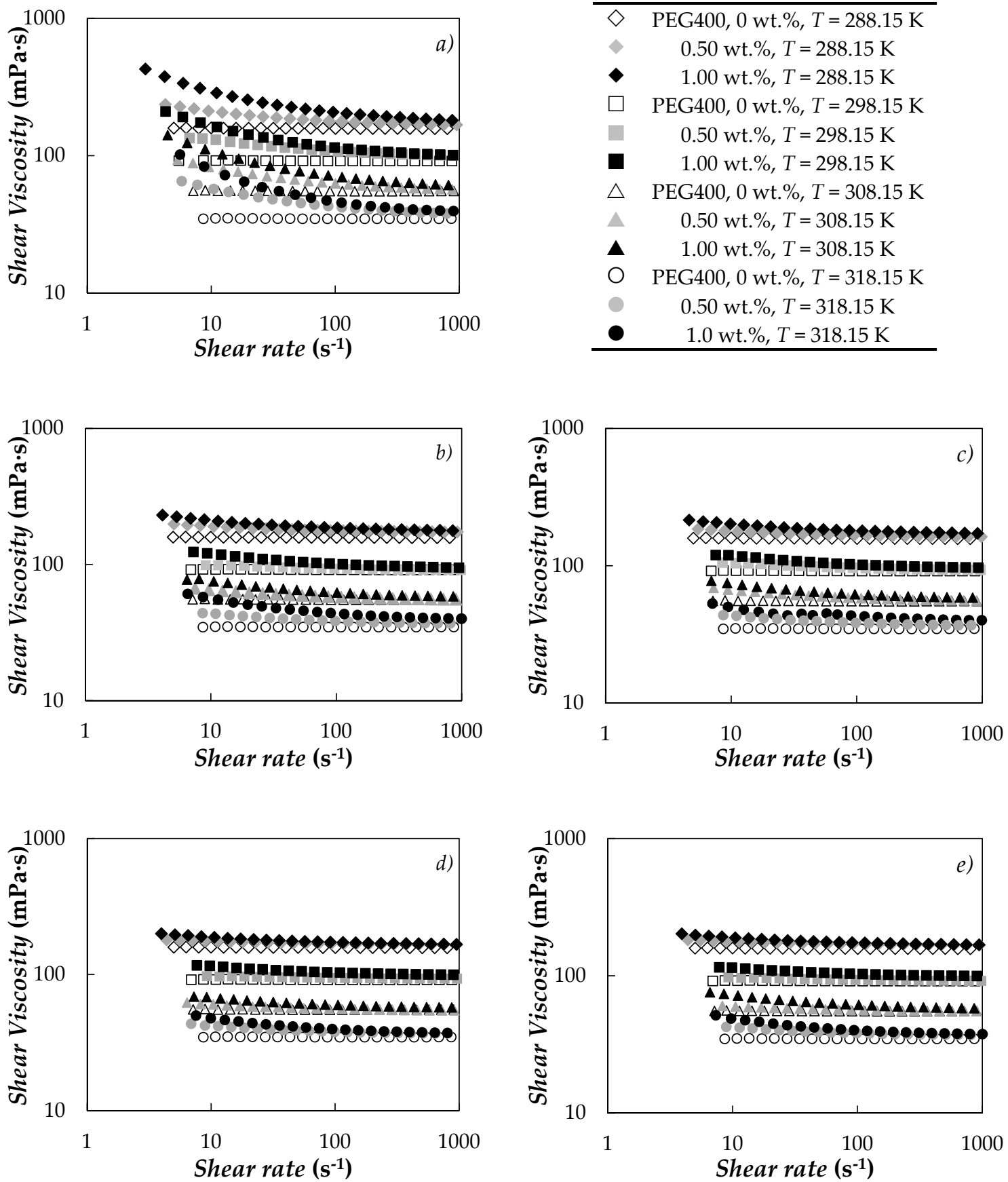

Figure 5. Flow viscosity curves of PEG400-based nanofluids containing: (a) CB, (b) nD87, (c) nD97, (d) G/D-p or (e) G/D-r carbon nanostructures.

The stronger pseudo-plastic behavior of carbon black suspensions can be attributed to the larger size and more irregular shape of those particles in comparison with the other four nanopowders. Small differences in the shear rate-shear viscosity curves when comparing the two nano-diamond sets (nD87 and nD97) or the two graphite/diamond nanomixture series (G/D-p and G/D-r) were attributed to different purity degrees or the ash content in the nanopowder by other authors $[81,83,92]$ for studied ethylene glycol suspensions with higher concentrations of those same nanoadditives. 
Table 3. Flow consistency factor $(n)$, flow behavior index $(K)$ and absolute average deviations (AAD\%) obtained from the Ostwald-de Waele equation, Equation (2), modelling the shear-thinning region up to $100 \mathrm{~s}^{-1}$ of the different studied dispersions.

\begin{tabular}{|c|c|c|c|c|c|c|c|c|c|c|}
\hline \multirow[b]{2}{*}{ Parameter } & \multicolumn{2}{|c|}{ CB } & \multicolumn{2}{|c|}{ nD87 } & \multicolumn{2}{|c|}{ nD97 } & \multicolumn{2}{|c|}{ G/D-p } & \multicolumn{2}{|c|}{ G/D-r } \\
\hline & $\begin{array}{c}0.5 \\
\text { wt. } \%\end{array}$ & $\begin{array}{c}1.0 \\
\text { wt. } \%\end{array}$ & $\begin{array}{c}0.5 \\
\text { wt. } \%\end{array}$ & $\begin{array}{c}1.0 \\
\text { wt. } \%\end{array}$ & $\begin{array}{c}0.5 \\
\text { wt. } \%\end{array}$ & $\begin{array}{c}1.0 \\
\text { wt. } \%\end{array}$ & $\begin{array}{c}0.5 \\
\text { wt. } \%\end{array}$ & $\begin{array}{c}1.0 \\
\text { wt. } \%\end{array}$ & $\begin{array}{c}0.5 \\
\text { wt. } \%\end{array}$ & $\begin{array}{c}1.0 \\
\text { wt. } \%\end{array}$ \\
\hline & \multicolumn{10}{|c|}{$T=288.15 \mathrm{~K}$} \\
\hline$K\left(\mathrm{mPa} \cdot \mathrm{s}^{\mathrm{n}}\right)$ & 262.91 & 480.82 & 203.49 & 243.45 & 191.56 & 225.13 & 186.03 & 211.33 & 186.64 & 213.41 \\
\hline$n$ & 0.91 & 0.80 & 0.97 & 0.95 & 0.97 & 0.95 & 0.98 & 0.95 & 0.98 & 0.95 \\
\hline \multirow[t]{2}{*}{$\mathrm{AAD} \%$} & 0.8 & 2.2 & 0.3 & 1.3 & 0.4 & 0.6 & 0.1 & 0.4 & 0.2 & 0.3 \\
\hline & \multicolumn{10}{|c|}{$T=298.15 \mathrm{~K}$} \\
\hline$K\left(\mathrm{mPa} \cdot \mathrm{s}^{\mathrm{n}}\right)$ & 161.13 & 269.64 & 106.86 & 142.99 & 116.65 & 135.98 & 100.07 & 128.66 & 101.59 & 127.45 \\
\hline$n$ & 0.91 & 0.79 & 0.97 & 0.94 & 0.96 & 0.94 & 0.99 & 0.95 & 0.98 & 0.95 \\
\hline \multirow[t]{2}{*}{$\mathrm{AAD} \%$} & 0.6 & 2.2 & 0.1 & 0.4 & 0.3 & 0.6 & 0.2 & 0.3 & 0.1 & 0.4 \\
\hline & \multicolumn{10}{|c|}{$T=308.15 \mathrm{~K}$} \\
\hline$K\left(\mathrm{mPa} \cdot \mathrm{s}^{\mathrm{n}}\right)$ & 100.41 & 178.29 & 72.05 & 82.30 & 76.82 & 89.73 & 64.94 & 75.82 & 63.46 & 76.82 \\
\hline$n$ & 0.90 & 0.78 & 0.97 & 0.92 & 0.94 & 0.92 & 0.96 & 0.95 & 0.97 & 0.94 \\
\hline \multirow[t]{2}{*}{$\mathrm{AAD} \%$} & 0.7 & 2.2 & 0.4 & 0.1 & 0.4 & 0.8 & 0.9 & 0.3 & 0.1 & 0.3 \\
\hline & \multicolumn{10}{|c|}{$T=318.15 \mathrm{~K}$} \\
\hline$K\left(\mathrm{mPa} \cdot \mathrm{s}^{\mathrm{n}}\right)$ & 72.81 & 130.74 & 63.46 & 72.05 & 48.84 & 63.02 & 46.46 & 56.77 & 46.59 & 57.64 \\
\hline$n$ & 0.88 & 0.77 & 0.95 & 0.87 & 0.95 & 0.91 & 0.95 & 0.92 & 0.96 & 0.92 \\
\hline $\mathrm{AAD} \%$ & 1.1 & 4.2 & 0.4 & 1.1 & 0.5 & 3.8 & 1.4 & 0.9 & 0.4 & 1.0 \\
\hline
\end{tabular}

As expected, nanofluid viscosity rises with the addition of nanoparticles. Figure 6a shows the increases in dynamic viscosity for the two studied concentrations and five carbon-based structures regarding the base PEG400. At that shear rate a higher viscosity is observed for CB/PEG400 samples than for the sets containing nano-diamonds (nD87 and nD97) or graphite/diamond nanomixtures (G/D-p and G/D-r).
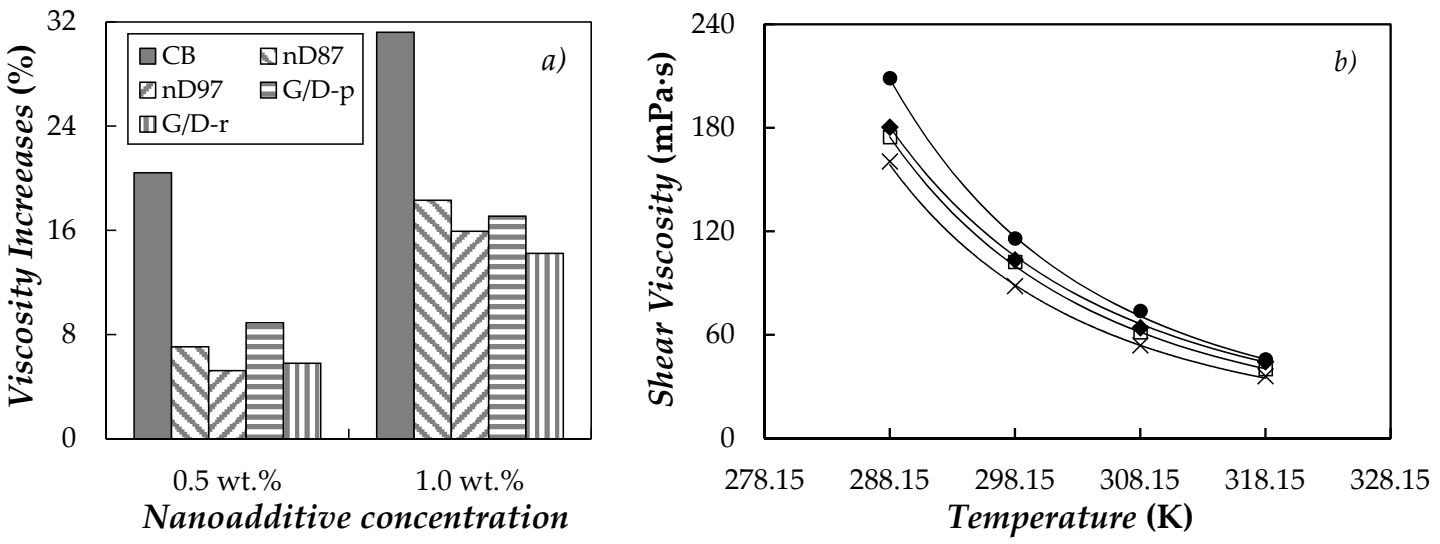

Figure 6. (a) Modifications in shear viscosity regarding neat PEG400 at $\sim 100 \mathrm{~s}^{-1}$ and $298.15 \mathrm{~K}$. (b) Temperature dependence of shear viscosity obtained at $\sim 100 \mathrm{~s}^{-1}$ for neat PEG400 $(\times)$ and nanofluids prepared at the highest nanoparticle concentration, $1.0 \mathrm{wt} . \%$, of $(\bullet)$ CB, (口) nD87 and (\$) G/D-p. (Solid lines) Vogel-Fulcher-Tammann-Hesse, Equation (3).

Figure $6 \mathrm{~b}$ shows the temperature dependence of the dynamic viscosities collected at a shear rate of $\sim 100 \mathrm{~s}^{-1}$ for CB/PEG400, nD87/PEG400 and G/D-p/PEG400, as an example. In the whole analyzed temperature range (288.15-318.15 K), reductions in dynamic viscosity with increasing temperatures are $\sim 75-79 \%$. The characteristic downward trend in the viscosity of liquids with rising temperature, $\eta(T)$, can be described by means of the following three-parameter logarithmic equation known as the Vogel-Fulcher-Tammann-Hesse [104-106] equation:

$$
\ln \eta(T)=\ln \eta_{0}+\frac{D \cdot T_{0}}{T-T_{0}}
$$


where $\eta_{0}, D$ and $T_{0}$ are the fitting coefficients, which provide physical information regarding the energy associated with packing of liquid molecules $\left(\eta_{0}\right)$, the dimensionless fragility of the liquid $(1 / D)$ and the ideal glass transition temperature $\left(T_{0}\right)$. The values of these coefficients as well as the $A A D \%$ and standard deviations between experimental values and data fitted by the Vogel-Fulcher-Tammann-Hesse model are gathered in Table 4.

Table 4. Fitting parameters $\left(\eta_{0}, D, T_{0}\right)$, absolute average deviations $(A A D \%)$ and standard deviation (s) obtained from the Vogel-Fulcher-Tammann-Hesse model, Equation (3), when modelling the temperature dependence of shear viscosity obtained at $\sim 100 \mathrm{~s}^{-1}$ for neat PEG400 and carbon-based PEG400 dispersions.

\begin{tabular}{ccccccc}
\hline \multirow{2}{*}{ Set } & \multirow{2}{*}{ Nanoparticle/wt. $\%$} & \multicolumn{3}{c}{ Fitting Parameters } & \multirow{2}{*}{ AAD $\%$} & s/mPa.s \\
\cline { 3 - 5 } & & $\boldsymbol{\eta}_{\mathbf{0}} / \mathbf{m P a} \mathbf{s}$ & $\boldsymbol{D}$ & $\boldsymbol{T}_{\mathbf{0}} / \mathbf{K}$ & & \\
\hline PEG400 & 0 & 0.0556 & 6.23 & 161.68 & 1.3 & 2.2 \\
CB & 0.5 & 0.0773 & 6.37 & 158.16 & 1.1 & 3.7 \\
nD87 & 0.5 & 0.0580 & 6.37 & 158.16 & 1.3 & 3.5 \\
nD97 & 0.5 & 0.0724 & 6.26 & 161.15 & 2.0 & 4.3 \\
G/D-p & 0.5 & 0.0718 & 6.35 & 161.15 & 0.7 & 2.9 \\
G/D-r & 0.5 & 0.0718 & 6.35 & 161.15 & 1.2 & 3.0 \\
CB & 1.0 & 0.0886 & 6.46 & 161.15 & 1.5 & 3.4 \\
nD87 & 1.0 & 0.0551 & 6.19 & 158.16 & 1.1 & 3.7 \\
nD97 & 1.0 & 0.0553 & 6.16 & 158.16 & 1.5 & 4.0 \\
G/D-p & 1.0 & 0.0572 & 6.18 & 158.16 & 2.0 & 3.0 \\
G/D-r & 1.0 & 0.0748 & 6.25 & 161.15 & 0.7 & 2.9 \\
\hline
\end{tabular}

Obtained experimental viscosities can be correlated with standard deviations in the range from 2.2 to $4.3 \mathrm{mPa} \cdot \mathrm{s}$ (AADs\% 0.7-2.0\%). Angell strength $(D)$ values are in the range 6.16-6.46, which correspond to liquids with moderate to fragile behavior [107].

\subsection{Thermal Conductivity}

Thermal conductivity, $k$, was studied for the base fluid and the ten carbon-based dispersions in the temperature range from 288 to $318 \mathrm{~K}$. Results here obtained for neat PEG400 exhibit a good agreement (AADs\% lower than 1.0\%) with previous data measured by Marcos et al. $[67,71,73]$ for poly(ethylene glycol) with similar molecular masses using other experimental devices based on the transient hot wire [71,73] or transient plane [67] methods. As an example, Figure 7a presents the temperature dependence of thermal conductivity for a PEG400 nanofluid set prepared with the purified graphite/diamond nanomixture (G/D-p).
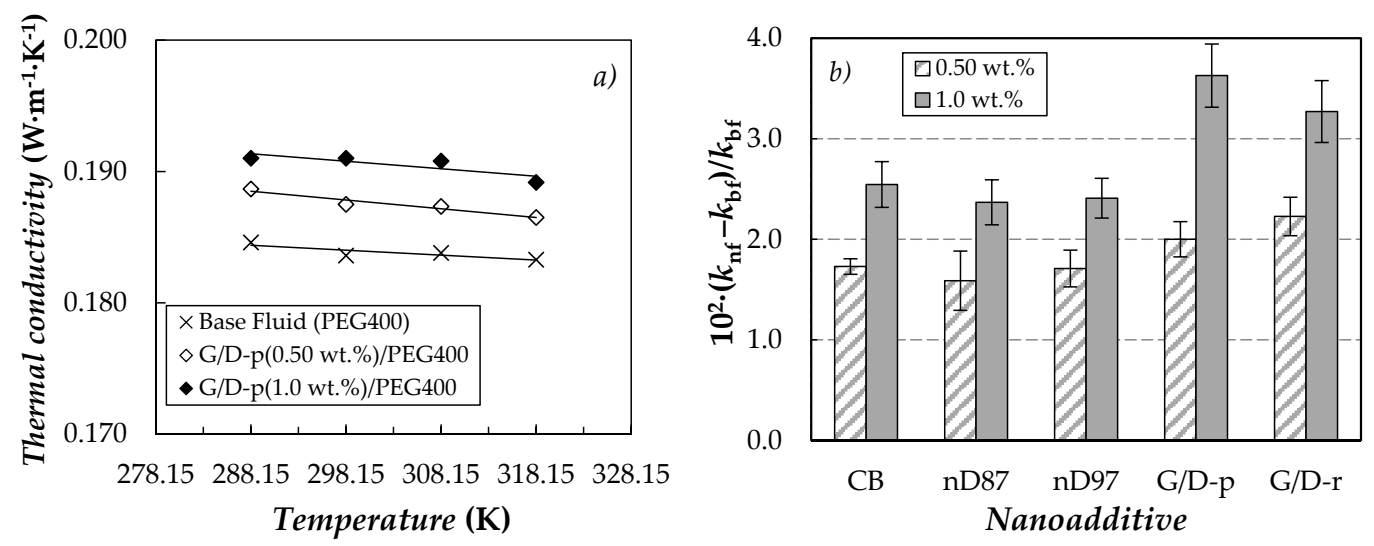

Figure 7. (a) Temperature dependence of thermal conductivity for (G/D-p)/PEG400 nanofluid system. (b) Average thermal conductivity enhancements regarding base PEG400, $10^{2} \cdot\left(k_{\mathrm{nf}}-k_{\mathrm{bf}}\right) / k_{\mathrm{nf}}$. Error bars represent the standard deviation between values obtained for the different studied temperatures. 
As can be observed, the thermal conductivity of the phase change materials slightly improves with the addition of carbon-based nanoparticles. Improvements in this property reach $2.0 \%$ and $3.6 \%$ for the sample loaded with $0.5 \%$ and $1.0 \%$ of G/D-p, respectively (see Figure $7 \mathrm{~b}$ ). The enhancements in thermal conductivity presented here are lower than the increases of $12.7 \%$ and $23 \%$ reported for PEG400-based nanofluids containing $1 \mathrm{wt}$ \% of MWCNTs [71] or $0.50 \mathrm{wt}$ \% of functionalized graphene nanoplatelets [73], respectively. Nevertheless, our $k$ modifications are similar to the maximum enhancement of 3.9\% reported for a $1.1 \mathrm{wt}$ \% suspension of PVP-capped silver nanoparticles in PEG400 [67].

\subsection{Volumetric Behavior}

Densities, $\rho$, of neat PEG400 and the five carbon-based suspensions were experimentally measured at atmospheric pressure and in the temperature range from 288.15 to $313.15 \mathrm{~K}$. As an example, experimental results obtained for the base fluid and the dispersions prepared with the highest concentration (1.0 wt.\%) of either carbon black (CB), nano-diamonds purified with grade G (nD87) or purified graphite/diamond nanomixture (G/D-p) are presented as a function of temperature in Figure 8 a.

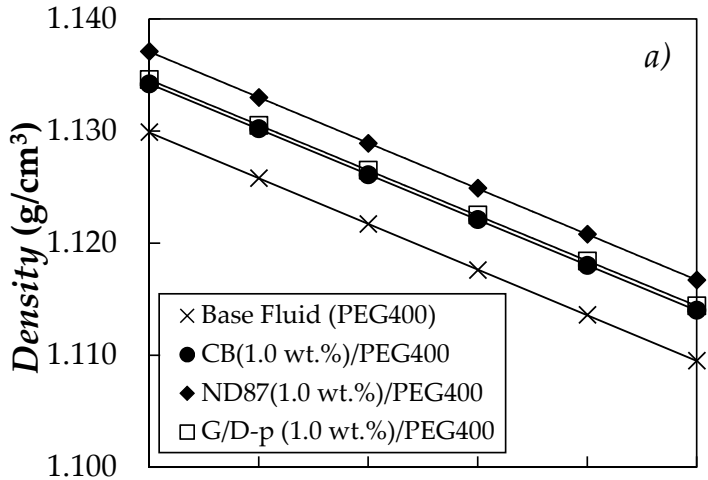

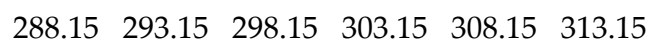
Temperature (K)

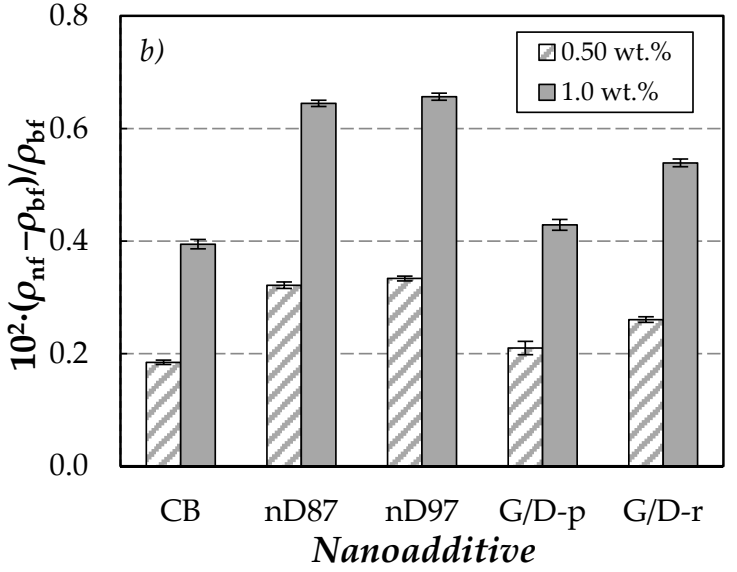

c)

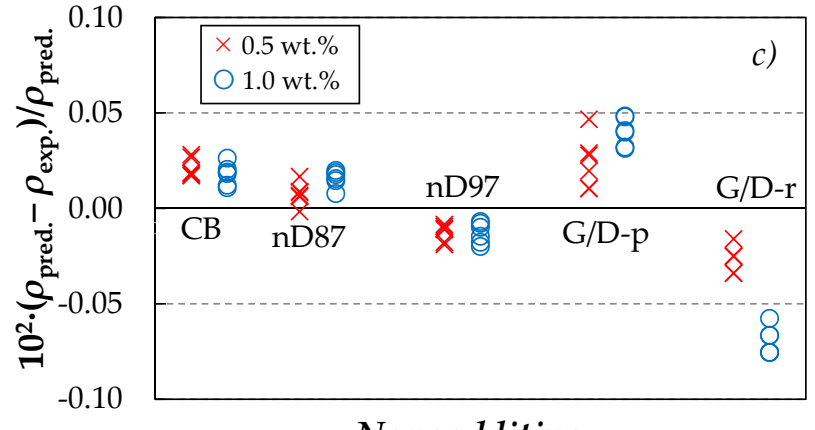

Nanoadditive

Figure 8. (a) Temperature dependence of density for neat PEG400 and nanofluids prepared at the highest nanoparticle concentration, $1.0 \mathrm{wt}$.\%, of $(\bullet)$ CB, () nD87 and ( $\bullet$ G/D-p. (b) Average density modifications regarding base PEG400, $10^{2} \cdot\left(\rho_{\mathrm{nf}}-\rho_{\mathrm{bf}}\right) / \rho_{\mathrm{nf}}$. Error bars represent the standard deviation between values obtained for the different studied temperatures. (c) Deviations between experimental densities, $\rho_{\text {exp., }}$ and values predicted using Equation (4), $\rho_{\text {pred }}$.

Maximum deviations lower than $0.05 \%$ were observed when the densities obtained for PEG400 in the framework of this investigation were compared with results reported in the literature [73,108-110] for poly(ethylene glycols) with similar molecular mass. Density increases with the increasing nanoparticle concentration, without any temperature effect on such enhancements. Average density modifications 
(regarding neat PEG400) obtained for the five different carbon-based nanofluid sets are plotted in Figure $8 \mathrm{~b}$. Higher $\rho$ enhancements were observed for suspensions containing purified nano-diamonds (nD87 and nD97) than for the rest of carbon-based nanostructures. This result can be attributed to the higher density of nano-diamonds (usually in the range of $3.1-3.3 \mathrm{~g} \cdot \mathrm{cm}^{-3}$ [84]), when compared to graphite or carbon black $\left(1.9-2.3 \mathrm{~g} \cdot \mathrm{cm}^{-3}\right.$ reported elsewhere [82]). Modifications presented here are in parallel with the maximum enhancement of $0.33 \%$ reported for a $0.5 \mathrm{wt} . \%$ (graphene nanoplatelet)/PEG dispersion by Marcos et al. [73] or the increase of $0.42 \%$ obtained for MWCNT(1 wt.\%)/PEG400 in [71]. A good agreement was also found between density modifications here reported for nD87/PEG400 and nD97/PEG400 and those previous measured for nD87/EG and nD97/EG suspensions by Żyła et al. [92]. Experimental $\rho$ measured in this work for PEG400-based suspensions were also compared with the values calculated using the following weight-average equation:

$$
\frac{1}{\rho_{\mathrm{nf}}}=\frac{\varphi}{\rho_{\mathrm{np}}}-\frac{1-\varphi}{\rho_{\mathrm{bf}}}
$$

where $\varphi$ is the mass fraction of the nanoparticles, while the subscripts $\mathrm{nf}$, bf and $\mathrm{np}$ stand for nanofluid, base fluid and nanoparticles, respectively. In this case, nanoparticle densities of 1.9, 3.1, 3.2, 2.52 and $2.54 \mathrm{~g} / \mathrm{cm}^{-3}$ were considered for carbon back (CB) [82], nano-diamonds purified with grade $\mathrm{G}$ (nD87), nano-diamonds purified with grade G01 (nD97), purified graphite/diamond nanomixture, (G/D-p) [83] and raw graphite/diamond nanomixture (G/D-r) [83], respectively. The densities for the two nano-diamond mixtures were calculated as the weight average value between the densities of graphite $\left(2.26 \mathrm{~g} / \mathrm{cm}^{-3}\right.$ [82] $)$ and nano-diamonds $\left(3.2 \mathrm{~g} \cdot \mathrm{cm}^{-3}\right.$ [84]), considering the amount of nano-diamonds (87 and $97 \%$ in mass) and impurities (all assumed with the same density as graphite). As shown in Figure $8 c$, deviations between experimental densities and values predicted using Equation (4) are within $0.1 \%$.

Like for the base fluid, the nanofluid densities decrease as temperature increases. This $\rho(T)$-dependence can be correlated with AADs $\%$ lower than $0.001 \%$ by means of second-order polynomial fittings. Isobaric thermal expansivities, $\alpha_{\mathrm{p}}=-(1 / \rho)(\partial \rho / \partial T)_{\mathrm{p}}$, can be numerically calculated from the derivatives of those polynomial density adjustments. At the studied conditions, the obtained values are in the range $(7.15-7.45) \times 10^{-4} \cdot \mathrm{K}^{-1}$. This property mainly reduces with the nanoparticle loading, with maximum diminutions reaching $1.2 \%$ and $1.4 \%$ for CB (1.0 wt.\%)/PEG400 and G/D-r (1.0 wt.\%)/PEG400 samples, respectively. In comparison with liquids, solid carbon materials are well known to show high elastic stiffness when subject to changes in temperature. Thus, at room temperature single crystal diamond exhibits an isobaric thermal expansion coefficient around $(7 \pm 3) \times 10^{-7} \cdot \mathrm{K}^{-1}$, for example. According to a weight rule mixture based on the volume fraction of the nanoparticles, i.e., $\alpha_{\mathrm{p}, \mathrm{nf}}=\phi \cdot \alpha_{\mathrm{p}, \mathrm{np}}+(1-\phi) \cdot \alpha_{\mathrm{p}, \mathrm{bf}}$, the addition of carbon-based nanostructures is expected to reduce apparent thermal conductivity. Such behavior was observed in the literature for graphene dispersions into ethylene glycol-water mixtures [73,111] or poly(ethylene glycol) [112], for instance. However, dissimilar results were also reported. Thus, some authors $[103,113]$ observed reductions in the isobaric heat capacity when adding nanoparticles. Such changes may be attributed to a minor degree of cohesion in relation to base fluids, due to the presence of surfactant molecules or possible interactions between base fluid and solid nanoparticles.

\subsection{Surface Tension}

Surface tension, SFT or $\sigma$, measurements of base PEG400 and the ten nano-dispersions were performed in the temperature range from 288 to $318 \mathrm{~K}$ by means of the DSA-30 drop-shape analyzer. Following the investigation recently published by Wanic et al. [93], experimental STFs were also determined at 298 and $308 \mathrm{~K}$ for samples loaded with $1.0 \mathrm{wt}$ \% using a PI-MT1A.KOM Du Noüy ring surface tensiometer. As an example, Figure 9 shows the temperature dependence of surface tension for the base fluid and nanofluids containing 1.0\% concentrations of either carbon black (CB), nano-diamonds purified with grade $G(n D 87)$ or purified graphite/diamond nanomixture (G/D-p). 


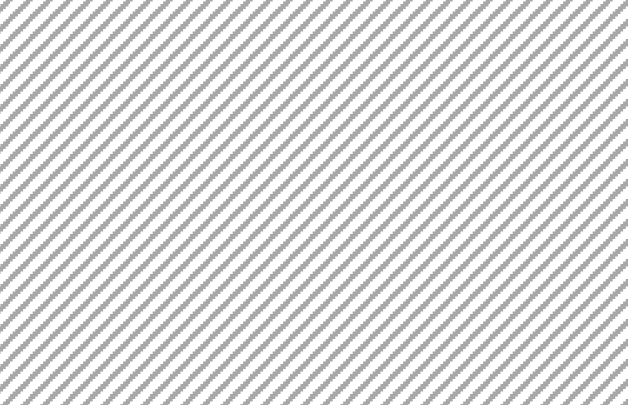

\begin{tabular}{cc}
\hline$\bigcirc$ & PEG400, 0 wt.\%, Pendant Drop \\
$\bigcirc$ & PEG400, 0 wt.\%, Ring \\
$\triangle$ & 1.0 wt. $\%$, Pendant Drop \\
$\triangle$ & 1.0 wt.\%, Ring \\
\hline
\end{tabular}

$\begin{array}{llllll}278.15 & 288.15 & 298.15 & 308.15 & 318.15 & 328.15\end{array}$

Temperature $(\mathrm{K})$
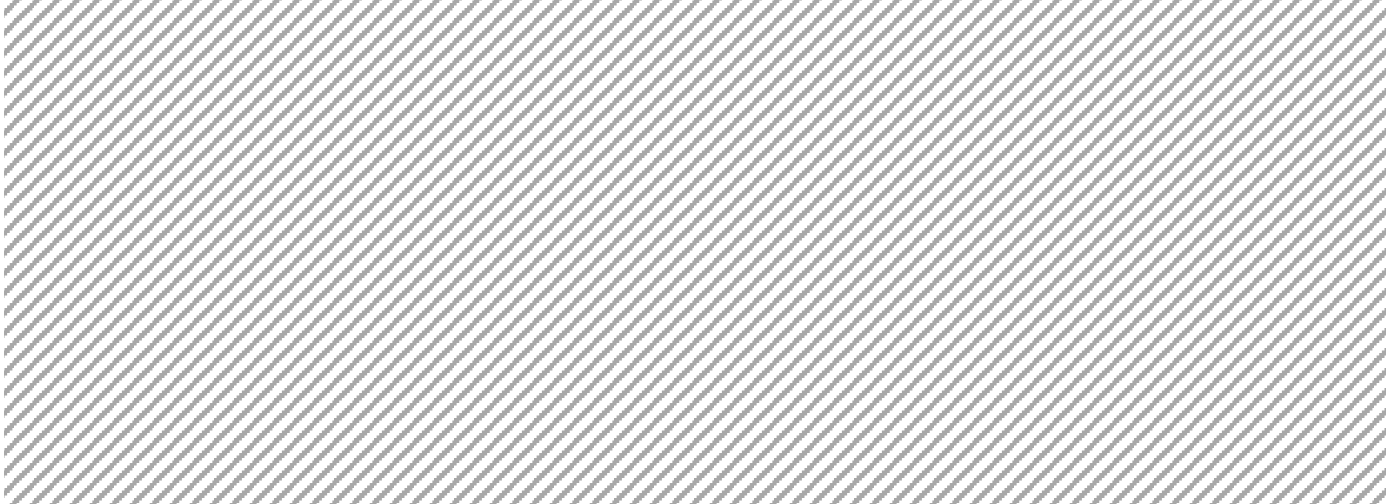

Figure 9. Temperature dependence of surface tension obtained for neat PEG400 and nanofluids prepared at the highest nanoparticle concentration, 1 wt.\%, of (a) CB, (b) nD87 and (c) G/D-p.

A good agreement was found between the experimental results determined in this investigation for the base fluid (PEG400) and previous SFTs reported for poly(ethylene glycol)s with close molecular mass by Fu et al. [114] or Marcos et al. [67]. A comparison between the values provided for both base PEG400 and $1.0 \mathrm{wt} . \%$ samples by Du Noüy ring and drop-shape surface tensiometers shows deviations lower than or equal to $0.9 \%$, which is well within the combined experimental uncertainty of both devices. Carbon-based suspensions present the same downward trend with increasing temperature as exhibited by the neat PEG400. In the studied interval (288-318 K), SFT reductions with rising temperature are $2.1-2.7 \%$ each $10 \mathrm{~K}$. Regarding the nanoparticle loading effect on SFT, different behaviors can be observed depending on the carbon nanostructure. Average modifications in surface tension (regarding the base fluid) for the different samples are presented in Figure 10.

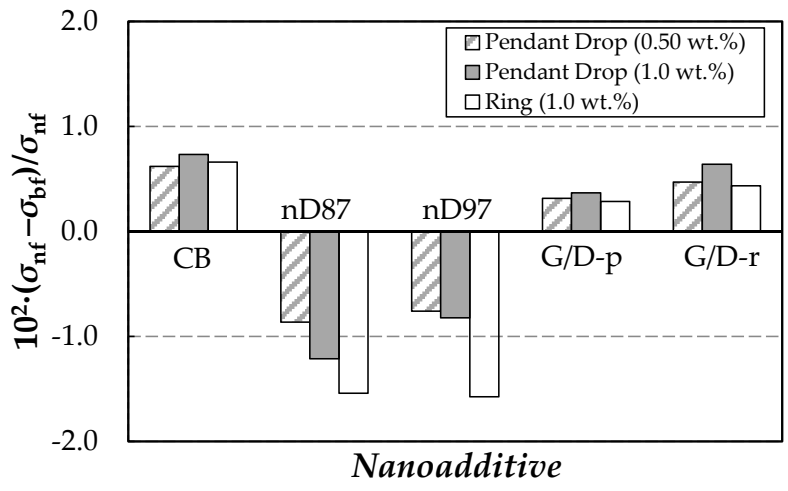

Figure 10. Average modifications in surface tension regarding pure PEG400, $10^{2} \cdot\left(\sigma_{\mathrm{nf}}-\sigma_{\mathrm{bf}}\right) / \sigma_{\mathrm{nf}}$, obtained for the 0.50 and $1.0 \mathrm{wt} . \%$ nanofluids using the pendant drop method and for $1.0 \mathrm{wt} . \%$ nanofluids using the ring method. 
Reductions in SFT were obtained for the two nano-diamond nanopowders (nD87 and nD97), while slight increases were observed for dispersions prepared using the other three carbon-based nanopowders. However, it must be pointed out that, except for results obtained for $1.0 \%$ concentrations of nD87/PEG and nD97/PEG sets using the Du Noüy ring method and 1.0\% loading of nD87/PEG using the drop-shape analyzer, all modifications are within the experimental uncertainties reported by these devices $1.0 \%$ [93].

\section{Conclusions}

In this paper, phase change materials based on PEG400 and containing five different carbon-based materials (viz., a carbon black nanopowder, two graphite/diamond nanomixtures and two nano-diamond nanopowders with two different purity grades) are thermally and physically characterized as potential phase change materials to cold energy storage media. First, mechanical and thermal changes occurring during the solid-liquid phase transition were analyzed throughout differential scanning calorimetry and oscillatory rheology studies. The dispersion of nanoparticles reduced the undesirable sub-cooling effect from $4.0 \mathrm{~K}$ (neat-PEG400) to $2.3 \mathrm{~K}$ (carbon black dispersion at $1.0 \mathrm{wt} . \%$ ) or $2.0 \mathrm{~K}$ (raw graphite/diamond nanomixture suspension at $1.0 \mathrm{wt} . \%$ ). A good agreement (less than $0.8 \mathrm{~K}$ ) was observed between the crystallizing temperatures determined using DSC and detected during dynamic oscillatory rheological tests. The effects of particle loading (0.5 wt.\% and 1.0 wt.\%) and carbon nanostructure type (CB, nD87, nD97, G/D-p and G/D-r) on dynamic viscosity, thermal conductivity, density and surface tension were also investigated in the temperature range from 288.15 to $318.15 \mathrm{~K}$. According to the non-linear rheological experiments, all studied suspensions showed a non-Newtonian pseudo-plastic behavior. Shear-thinning degree rose with increasing nanoparticle loading and was stronger in the case of carbon black (CB) dispersions, followed by nano-diamond sets (nD87 and nD97) and finally graphite/diamond nano-mixtures (G/D-p and G/D-r). Larger thermal conductivity improvements were observed in the case of suspensions containing purified (3.6\%) and raw (3.3\%) graphite/diamond nanomixtures, while $\mathrm{nD} 87$ and nD97 nano-diamond suspensions showed the maximum modifications in density (increases of up to $0.64-0.66 \%$ ). A good agreement was observed between surface tension measurements performed using drop-shape analyzer and Du Noüy ring methods. Reductions in this property were observed for the two nano-diamond nanopowders (nD87 and nD97), while slight increases (within experimental uncertainties) were observed for dispersions prepared using the other three carbon-based nanopowders. Analyzing the effect that the chemical functionalization of the nanoparticles could have on the phase change characteristics and thermal behavior of the nano-enhanced phase change materials should be considered in future works. Additionally, non-dimensional analyses or economic studies could help to optimize the most appropriate concentration of nanoparticles.

Author Contributions: Data curation, J.F. and M.A.M.; investigation, D.C., S.H., J.F. and M.A.M.; methodology, P.E. and G.Ż.; writing-original draft, D.C. and S.H.; writing—review and editing, P.E. and G.Ż. All authors have read and agreed to the published version of the manuscript.

Funding: Research was partially supported by EU COST Action CA15119: Overcoming Barriers to Nanofluids Market Uptake. David Cabaleiro was a recipient of a postdoctoral fellowship from Xunta de Galicia (Spain) and acknowledges EU COST for the STSM Grant Ref. COST-STSM-CA15119-42918. Samah Hamze acknowledges EU COST for the STMS grant ref. COST-STSM-CA15119-45590. Marco Antonio Marcos acknowledges EU COST for the STMS grant ref. COST-STSM-CA15119-45123. Patrice Estellé acknowledges the European Union through the European Regional Development Fund (ERDF), the Ministry of Higher Education and Research and the French region of Brittany and Rennes Métropole for the financial support of surface tension experimental device. This work was also supported by the Ministerio de Economía y Competitividad (Spain) and FEDER program through ENE2017-86425-C2-1-R project.

Acknowledgments: Authors acknowledge CACTI (Univ. de Vigo) and Michał Wanic (Rzeszow University of Technology) for technical assistance.

Conflicts of Interest: The authors declare no conflicts of interest. 


\section{Nomenclature}

\begin{tabular}{|c|c|}
\hline $\mathrm{AAD} \%$ & Absolute average deviation \\
\hline$\alpha_{\mathrm{p}}$ & Isobaric thermal expansivity $\left(\mathrm{K}^{-1}\right)$ \\
\hline $\mathrm{CB}$ & Carbon black \\
\hline$D, \eta_{0}, T_{0}$ & Vogel-Fulcher-Tammann-Hesse fitting coefficients \\
\hline DSC & Differential scanning calorimetry \\
\hline EG & Ethylene glycol \\
\hline G/D-p & Purified graphite/diamond nanomixture \\
\hline G/D-r & Raw graphite/diamond nanomixture \\
\hline$k$ & Thermal conductivity $\left(\mathrm{W} \cdot \mathrm{m}^{-1} \cdot \mathrm{K}^{-1}\right)$ \\
\hline$K$ & Flow consistency factor $\left(\mathrm{mPa} \cdot \mathrm{s}^{\mathrm{n}}\right)$ \\
\hline MWCNT & Multiwalled carbon nanotubes \\
\hline$n$ & Flow behavior index \\
\hline nD87 & Nano-diamonds, purified, grade G \\
\hline nD97 & Nano-diamonds, purified, grade G01 \\
\hline NePCM & Nano-enhanced phase change material \\
\hline PCM & Phase change material \\
\hline PEG & Poly(ethylene glycol) \\
\hline$T$ & Temperature $(\mathrm{K})$ \\
\hline TES & Thermal energy storage \\
\hline$\beta$ & Heating/cooling rate $\left(\mathrm{K} \cdot \mathrm{min}^{-1}\right)$ \\
\hline$\Delta H$ & Latent heat $\left(\mathrm{J} \cdot \mathrm{g}^{-1}\right)$ \\
\hline$\eta$ & Dynamic viscosity (mPa.s) \\
\hline$\rho$ & Density $\left(\mathrm{g} \cdot \mathrm{cm}^{-3}\right)$ \\
\hline$\sigma$ & Surface tension, SFT, $(\mathrm{mN} \cdot \mathrm{m})$ \\
\hline$\varphi$ & Mass fraction \\
\hline$\phi$ & Volume fraction \\
\hline nD97 & Nano-diamonds, purified, grade G01 \\
\hline G/D-p & Purified graphite/diamond nanomixture \\
\hline G/D-r & Raw graphite/diamond nanomixture. \\
\hline$X_{\mathrm{C}}$ & Crystallinity degree \\
\hline$p$ & Pressure (MPa) \\
\hline$S$ & Standard deviation \\
\hline wt. $\%$ & Mass concentration \\
\hline \multicolumn{2}{|c|}{ Subscripts } \\
\hline bf & Base fluid \\
\hline cryst. & Crystallization \\
\hline melt. & Melting \\
\hline $\mathrm{nf}$ & Nanofluid \\
\hline $\mathrm{np}$ & Nanoparticle \\
\hline \multicolumn{2}{|c|}{ Superscript } \\
\hline 0 & $100 \%$ crystallinity \\
\hline
\end{tabular}

\section{References}

1. Heun, M.K.; Brockway, P.E. Meeting 2030 primary energy and economic growth goals: Mission impossible? Appl. Energy 2019, 251, 1-24. [CrossRef]

2. IEA. World Energy Statistics and Balance 2020 (Database); IEA: Paris, France, 2020.

3. Randolph, J.; Masters, G.M. Energy Sources and Sustainability. In Energy for Sustainability: Foundations for Technology, Planning, and Policy; Island Press/Center for Resource Economics: Washington, DC, USA, 2018; pp. 25-57, ISBN 978-1-61091-821-3.

4. Frigione, M.; Lettieri, M.; Sarcinella, A. Phase change materials for energy efficiency in buildings and their use in mortars. Materials 2019, 12, 1260. [CrossRef] [PubMed]

5. IRENA. Global Energy Transformation: A Roadmap to 2050; IRENA: Abu Dhabi, UAE, 2018. 
6. Alva, G.; Lin, Y.; Fang, G. An overview of thermal energy storage systems. Energy 2018, 144, 341-378. [CrossRef]

7. Languri, E.M.; Cunningham, G. Thermal Energy Storage Systems. In Advances in Sustainable Energy; Vasel, A., Ting, D.S.K., Eds.; Springer International Publishing: New York, NY, USA, 2019; pp. 169-176, ISBN 978-3-030-05636-0.

8. Cabeza, L.F.; Castell, A.; Barreneche, C.; De Gracia, A.; Fernández, A.I. Materials used as PCM in thermal energy storage in buildings: A review. Renew. Sustain. Energy Rev. 2011, 15, 1675-1695. [CrossRef]

9. Pardiñas, Á.; Alonso, M.J.; Diz, R.; Kvalsvik, K.H.; Fernández-Seara, J. State-of-the-art for the use of phase-change materials in tanks coupled with heat pumps. Energy Build. 2017, 140, 28-41. [CrossRef]

10. Rashidi, S.; Shamsabadi, H.; Esfahani, J.A.; Harmand, S. A review on potentials of coupling PCM storage modules to heat pipes and heat pumps. J. Therm. Anal. Calorim. 2019, 140, 1655-1713. [CrossRef]

11. Pielichowska, K.; Pielichowski, K. Phase change materials for thermal energy storage. Prog. Mater. Sci. 2014, 65, 67-123. [CrossRef]

12. Abokersh, M.H.; Omnia El-Baz, M.O.; El-Morsi, M.; Sharaf, O. Review of the phase change material (PCM) usage for solar domestic water heating systems (SDWHS). Int. J. Energy Res. 2017, 42, 329-357. [CrossRef]

13. Mofijur, M.; Mahlia, T.M.I.; Silitonga, A.S.; Ong, H.C.; Silakhori, M.; Hasan, M.H.; Putra, N.; Ashrafur Rahman, S.M. Phase change materials (PCM) for solar energy usages and storage: An overview. Energies 2019, 12, 3167. [CrossRef]

14. Forcescue, P.; Swinerd, G.; Stark, J. Spacecraft Systems Engineering, 4th ed.; John Wiley \& Sons, Ldt.: London, UK, 2011.

15. Cabeza, L.F. Thermal Energy Storage. Compr. Renew. Energy 2012, 3, 211-253.

16. Sarbu, I.; Sebarchievici, C. Solar Heating and Cooling Systems: Fundamentals, Experiments and Applications; Elsevier: Oxford, UK, 2017.

17. Navarro, L.; de Gracia, A.; Colclough, S.; Browne, M.; McCormack, S.J.; Griffiths, P.; Cabeza, L.F. Thermal energy storage in building integrated thermal systems: A review. Part 1. active storage systems. Renew. Energy 2016, 88, 526-547. [CrossRef]

18. Souayfane, F.; Fardoun, F.; Biwole, P.H. Phase change materials (PCM) for cooling applications in buildings: A review. Energy Build. 2016, 129, 396-431. [CrossRef]

19. Du, K.; Calautit, J.; Wang, Z.; Wu, Y.; Liu, H. A review of the applications of phase change materials in cooling, heating and power generation in different temperature ranges. Appl. Energy 2018, 220, 242-273. [CrossRef]

20. Zalba, B.; Marín, J.M.; Cabeza, L.F.; Mehling, H. Review on thermal energy storage with phase change: Materials, heat transfer analysis and applications. Appl. Therm. Eng. 2003, 23, 251-283. [CrossRef]

21. Alkan, C.; Günther, E.; Hiebler, S.; Ensari, Ö.F.; Kahraman, D. Polyethylene glycol-sugar composites as shape stabilized phase change materials for thermal energy storage. Polym. Polym. Compos. 2012, 33, 1728-1736. [CrossRef]

22. Jiang, Y.; Ding, E.; Li, G. Study on transition characteristics of PEG/CDA solid-solid phase change materials. Polymer (Guildf). 2001, 43, 117-122. [CrossRef]

23. Qi, G.Q.; Yang, J.; Bao, R.Y.; Liu, Z.Y.; Yang, W.; Xie, B.H.; Yang, M.B. Enhanced comprehensive performance of polyethylene glycol based phase change material with hybrid graphene nanomaterials for thermal energy storage. Carbon N. Y. 2015, 88, 196-205. [CrossRef]

24. Oró, E.; de Gracia, A.; Castell, A.; Farid, M.M.; Cabeza, L.F. Review on phase change materials (PCMs) for cold thermal energy storage applications. Appl. Energy 2012, 99, 513-533. [CrossRef]

25. Sundararajan, S.; Samui, A.B.; Kulkarni, P.S. Versatility of polyethylene glycol (PEG) in designing solid-solid phase change materials (PCMs) for thermal management and their application to innovative technologies. J. Mater. Chem. A 2017, 5, 18379-18396. [CrossRef]

26. Rashidi, S.; Samimifar, M.; Doranehgard, M.H.; Li, L.K.B. Organic Phase Change Materials. In Reference Module in Materials Science and Materials Engineering; Elsevier: Amsterdam, The Netherlands, 2020; ISBN 978-0-12-803581-8.

27. Zarei, M.J.; Bazai, H.; Sharifpur, M.; Mahian, O.; Shabani, B. The effects of fin parameters on the solidification of PCMs in a fin-enhanced thermal energy storage system. Energies 2020, 13, 198. [CrossRef]

28. Fan, L.; Khodadadi, J.M. Thermal conductivity enhancement of phase change materials for thermal energy storage: A review. Renew. Sustain. Energy Rev. 2011, 15, 24-46. [CrossRef] 
29. Bruno, F.; Belusko, M.; Liu, M.; Tay, N.H.S. Using solid-liquid phase change materials (PCMs) in thermal energy storage systems. Adv. Therm. Energy Storage Syst. 2015, 9, 201-246.

30. Sharifi, N.; Bergman, T.L.; Faghri, A. Enhancement of PCM melting in enclosures with horizontally-finned internal surfaces. Int. J. Heat Mass Transf. 2011, 54, 4182-4192. [CrossRef]

31. Firoozzadeh, M. Experimental and Analytical Study on Enhancing Efficiency of the Photovoltaic Panels Using Polyethylene-Glycol 600 (PEG 600) as a Phase Change Material. Iran. J. Energy Environ. 2019, 600, 23-32.

32. Firoozzadeh, M.; Shiravi, A.H.; Shafiee, M. Using polyethylene glycol as a phase change material and fins for the cooling of photovoltaic cells of the crystalline type. Amirkabir J. Mech. Eng. 2018, 50, 1-3.

33. Eslami, M.; Bahrami, M.A. Sensible and latent thermal energy storage with constructal fins. Int. J. Hydrogen Energy 2017, 42, 17681-17691. [CrossRef]

34. Mousavi Baygi, S.R.; Sadrameli, S.M. Thermal management of photovoltaic solar cells using polyethylene glycol 1000 (PEG1000) as a phase change material. Therm. Sci. Eng. Prog. 2018, 5, 405-411. [CrossRef]

35. Zhang, H.L.; Baeyens, J.; Degrève, J.; Cáceres, G.; Segal, R.; Pitié, F. Latent heat storage with tubular-encapsulated phase change materials (PCMs). Energy 2014, 76, 66-72. [CrossRef]

36. Velraj, R.; Seeniraj, R.V.; Hafner, B.; Faber, C.; Schwarzer, K. Heat transfer enhancement in a latent heat storage system. Sol. Energy 1999, 65, 171-180. [CrossRef]

37. Jurkowska, M.; Szczygieł, I. Review on properties of microencapsulated phase change materials slurries (mPCMS). Appl. Therm. Eng. 2016, 98, 365-373. [CrossRef]

38. Liu, Z.; Yu, Z.; Yang, T.; Qin, D.; Li, S.; Zhang, G.; Haghighat, F.; Joybari, M.M. A review on macro-encapsulated phase change material for building envelope applications. Build. Environ. 2018, 144, 281-294. [CrossRef]

39. Navarrete, N.; La Zara, D.; Goulas, A.; Valdesueiro, D.; Hernández, L.; van Ommen, J.R.; Mondragón, R. Improved thermal energy storage of nanoencapsulated phase change materials by atomic layer deposition. Sol. Energy Mater. Sol. Cells 2020, 206, 110322. [CrossRef]

40. Perepelkin, K.E. Fibre Composite Materials. Polymeric Fibre Composites, Basic Types, Principles. Fibre Chem. 2006, 38, 26-40.

41. Wang, W.; Yang, X.; Fang, Y.; Ding, J. Preparation and performance of form-stable polyethylene glycol/silicon dioxide composites as solid-liquid phase change materials. Appl. Energy 2009, 86, 170-174. [CrossRef]

42. Tang, B.; Wu, C.; Qiu, M.; Zhang, X.; Zhang, S. PEG/SiO $\mathrm{S}_{2}-\mathrm{Al}_{2} \mathrm{O}_{3}$ hybrid form-stable phase change materials with enhanced thermal conductivity. Mater. Chem. Phys. 2014, 144, 162-167. [CrossRef]

43. Chen, X.; Li, X.; Xia, X.; Sun, C.; Liu, R. Thermal Performance of a PCM-Based Thermal. Energies 2019, 12, 3275. [CrossRef]

44. Mahdi, J.M.; Nsofor, E.C. Melting enhancement in triplex-tube latent heat energy storage system using nanoparticles-metal foam combination. Appl. Energy 2017, 191, 22-34. [CrossRef]

45. Marani, A.; Nehdi, M.L. Integrating phase change materials in construction materials: Critical review. Constr. Build. Mater. 2019, 217, 36-49. [CrossRef]

46. Wang, J.; Yang, M.; Lu, Y.; Jin, Z.; Tan, L.; Gao, H.; Fan, S.; Dong, W.; Wang, G. Surface functionalization engineering driven crystallization behavior of polyethylene glycol confined in mesoporous silica for shape-stabilized phase change materials. Nano Energy 2016, 19, 78-87. [CrossRef]

47. Nomura, T.; Okinaka, N.; Akiyama, T. Impregnation of porous material with phase change material for thermal energy storage. Mater. Chem. Phys. 2009, 115, 846-850. [CrossRef]

48. Grandi, S.; Magistris, A.; Mustarelli, P.; Quartarone, E.; Tomasi, C.; Meda, L. Synthesis and characterization of $\mathrm{SiO}_{2}-\mathrm{PEG}$ hybrid materials. J. Non. Cryst. Solids 2006, 352, 273-280. [CrossRef]

49. Oh, C.; Do Ki, C.; Young Chang, J.; Oh, S.G. Preparation of PEG-grafted silica particles using emulsion method. Mater. Lett. 2005, 59, 929-933. [CrossRef]

50. Yang, H.; Feng, L.; Wang, C.; Zhao, W.; Li, X. Confinement effect of $\mathrm{SiO}_{2}$ framework on phase change of PEG in shape-stabilized PEG/SiO 2 composites. Eur. Polym. J. 2012, 48, 803-810. [CrossRef]

51. Yatskovskaya, O.V.; Baklanova, O.N.; Gulyaeva, T.I.; Drozdov, V.A.; Gorbunov, V.A. The effect of polyethylene glycol molecular weight on characteristics of the porous structure of silica materials. Prot. Met. Phys. Chem. Surf. 2013, 49, 216-221. [CrossRef]

52. Feng, L.; Zheng, J.; Yang, H.; Guo, Y.; Li, W.; Li, X. Preparation and characterization of polyethylene glycol/active carbon composites as shape-stabilized phase change materials. Sol. Energy Mater. Sol. Cells 2011, 95, 644-650. [CrossRef] 
53. Feng, L.; Zhao, W.; Zheng, J.; Frisco, S.; Song, P.; Li, X. The shape-stabilized phase change materials composed of polyethylene glycol and various mesoporous matrices (AC, SBA-15 and MCM-41). Sol. Energy Mater. Sol. Cells 2011, 95, 3550-3556. [CrossRef]

54. Wang, C.; Feng, L.; Li, W.; Zheng, J.; Tian, W.; Li, X. Shape-stabilized phase change materials based on polyethylene glycol/porous carbon composite: The influence of the pore structure of the carbon materials. Sol. Energy Mater. Sol. Cells 2012, 105, 21-26. [CrossRef]

55. Chen, X.; Gao, H.; Yang, M.; Dong, W.; Huang, X.; Li, A.; Dong, C.; Wang, G. Highly graphitized 3D network carbon for shape-stabilized composite PCMs with superior thermal energy harvesting. Nano Energy 2018, 49, 86-94. [CrossRef]

56. Kibria, M.A.; Anisur, M.R.; Mahfuz, M.H.; Saidur, R.; Metselaar, I.H.S.C. A review on thermophysical properties of nanoparticle dispersed phase change materials. Energy Convers. Manag. 2015, 95, 69-89. [CrossRef]

57. He, M.; Yang, L.; Lin, W.; Chen, J.; Mao, X.; Ma, Z. Preparation, thermal characterization and examination of phase change materials (PCMs) enhanced by carbon-based nanoparticles for solar thermal energy storage. J. Energy Storage 2019, 25, 100874. [CrossRef]

58. Colla, L.; Fedele, L.; Mancin, S.; Danza, L.; Manca, O. Nano-PCMs for enhanced energy storage and passive cooling applications. Appl. Therm. Eng. 2017, 110, 584-589. [CrossRef]

59. Ferrer, G.; Barreneche, C.; Solé, A.; Juliá, J.E.; Cabeza, L.F. Recent patents on nano-enhanced materials for use in thermal energy storage (TES). Recent Pat. Nanotechnol. 2017, 11, 101-108. [CrossRef] [PubMed]

60. Leong, K.Y.; Abdul Rahman, M.R.; Gurunathan, B.A. Nano-enhanced phase change materials: A review of thermo-physical properties, applications and challenges. J. Energy Storage 2019, 21, 18-31. [CrossRef]

61. COST Action CA15119 NanoUptake. Available online: http://www.nanouptake.eu/ (accessed on 24 October 2019).

62. Yapici, K.; Cakmak, N.K.; Ilhan, N.; Uludag, Y. Rheological characterization of polyethylene glycol based $\mathrm{TiO}_{2}$ nanofluids. Korea-Aust. Rheol. J. 2014, 26, 355-363. [CrossRef]

63. Zhang, H.; Yuan, Y.; Sun, Q.; Cao, X. Enhanced thermal energy storage performance of polyethylene glycol by using interfacial interaction of copper-based metal oxide. Adv. Eng. Mater. 2017, 19, 1600601. [CrossRef]

64. Zafarani-Moattar, M.; Majdan-Cegincara, R. Stability, rheological, magnetorheological and volumetric characterizations of polymer based magnetic nanofluids. Colloid Polym. Sci. 2013, 291, 1977-1987. [CrossRef]

65. Song, S.; Qiu, F.; Zhu, W.; Guo, Y.; Zhang, Y.; Ju, Y.; Feng, R.; Liu, Y.; Chen, Z.; Zhou, J.; et al. Polyethylene glycol/halloysite@Ag nanocomposite PCM for thermal energy storage: Simultaneously high latent heat and enhanced thermal conductivity. Sol. Energy Mater. Sol. Cells 2019, 193, 237-245. [CrossRef]

66. Deng, Y.; Li, J.; Qian, T.; Guan, W.; Li, Y.; Yin, X. Thermal conductivity enhancement of polyethylene glycol/expanded vermiculite shape-stabilized composite phase change materials with silver nanowire for thermal energy storage. Chem. Eng. J. 2016, 295, 427-435. [CrossRef]

67. Marcos, M.A.; Cabaleiro, D.; Hamze, S.; Fedele, L.; Bobbo, S.; Estellé, P.; Lugo, L. NePCM based on silver dispersions in poly(ethylene glycol) as a stable solution for thermal storage. Nanomaterials 2020, 10, 19. [CrossRef] [PubMed]

68. Popa, M.; Pradell, T.; Crespo, D.; Calderón-Moreno, J.M. Stable silver colloidal dispersions using short chain polyethylene glycol. Colloids Surf. A Physicochem. Eng. Asp. 2007, 303, 184-190. [CrossRef]

69. Tang, B.; Qiu, M.; Zhang, S. Thermal conductivity enhancement of PEG/SiO 2 composite PCM by in situ Cu doping. Sol. Energy Mater. Sol. Cells 2012, 105, 242-248. [CrossRef]

70. Tang, B.; Wang, Y.; Qiu, M.; Zhang, S. A full-band sunlight-driven carbon nanotube/PEG/SiO 2 composites for solar energy storage. Sol. Energy Mater. Sol. Cells 2014, 123, 7-12. [CrossRef]

71. Marcos, M.A.; Podolsky, N.E.; Cabaleiro, D.; Lugo, L.; Zakharov, A.O.; Postnov, V.N.; Charykov, N.A.; Ageev, S.V.; Semenov, K.N. MWCNT in PEG-400 nanofluids for thermal applications: A chemical, physical and thermal approach. J. Mol. Liq. 2019, 294, 1-13. [CrossRef]

72. Wang, C.; Chen, K.; Huang, J.; Cai, Z.; Hu, Z.; Wang, T. Thermal behavior of polyethylene glycol based phase change materials for thermal energy storage with multiwall carbon nanotubes additives. Energy 2019, 180, 873-880. [CrossRef]

73. Marcos, M.A.; Cabaleiro, D.; Guimarey, M.J.G.; Comuñas, M.J.P.; Fedele, L.; Fernández, J.; Lugo, L. PEG 400-based phase change materials nano-enhanced with functionalized graphene nanoplatelets. Nanomaterials 2018, 8, 16. [CrossRef] [PubMed] 
74. Qi, G.Q.; Liang, C.L.; Bao, R.Y.; Liu, Z.Y.; Yang, W.; Xie, B.H.; Yang, M.B. Polyethylene glycol based shape-stabilized phase change material for thermal energy storage with ultra-low content of graphene oxide. Sol. Energy Mater. Sol. Cells 2014, 123, 171-177. [CrossRef]

75. He, L.; Wang, H.; Zhu, H.; Gu, Y.; Li, X.; Mao, X. Thermal properties of PEG/graphene nanoplatelets (GnPs) Composite phase change materials with enhanced thermal conductivity and photo-thermal performance. Appl. Sci. 2018, 8, 2613. [CrossRef]

76. Cabaleiro, D.; Agresti, F.; Barison, S.; Marcos, M.A.; Prado, J.I.; Rossi, S.; Bobbo, S.; Fedele, L. Development of paraffinic phase change material nanoemulsions for thermal energy storage and transport in low-temperature applications. Appl. Therm. Eng. 2019, 159, 113868. [CrossRef]

77. Agresti, F.; Fedele, L.; Rossi, S.; Cabaleiro, D.; Bobbo, S.; Ischia, G.; Barison, S. Nano-encapsulated PCM emulsions prepared by a solvent-assisted method for solar applications. Sol. Energy Mater Sol. Cells 2019, 194, 268-275. [CrossRef]

78. Ranjbar, S.; Masoumi, H.; Khoshkhoo, R.H.; Mirfendereski, M. Experimental investigation of stability and thermal conductivity of phase change materials containing pristine and functionalized multi-walled carbon nanotubes. J. Therm. Anal. Calorim. 2019, 140, 2505-2518. [CrossRef]

79. Keshteli, A.N.; Sheikholeslami, M. Nanoparticle enhanced PCM applications for intensification of thermal performance in building: A review. J. Mol. Liq. 2019, 274, 516-533. [CrossRef]

80. Estellé, P.; Cabaleiro, D.; Żyła, G.; Lugo, L.; Murshed, S.M.S. Current trends in surface tension and wetting behavior of nanofluids. Renew. Sustain. Energy Rev. 2018, 94, 931-944. [CrossRef]

81. Vallejo, J.P.; Żyła, G.; Fernández-Seara, J.; Lugo, L. Influence of six carbon-based nanomaterials on the rheological properties of nanofluids. Nanomaterials 2019, 9, 146. [CrossRef] [PubMed]

82. Charreteur, F.; Jaouen, F.; Ruggeri, S.; Dodelet, J.P. Fe/N/C non-precious catalysts for PEM fuel cells: Influence of the structural parameters of pristine commercial carbon blacks on their activity for oxygen reduction. Electrochim. Acta 2008, 53, 2925-2938. [CrossRef]

83. Żyła, G.; Fal, J.; Estellé, P. The influence of ash content on thermophysical properties of ethylene glycol based graphite/diamonds mixture nanofluids. Diam. Relat. Mater. 2017, 74, 81-89. [CrossRef]

84. Vereshchagin, L.A.; Sakovich, G.V. Structure of detonation nanodiamonds. Mendeleev Commun. 2001, 11, 39-41. [CrossRef]

85. Cabaleiro, D.; Gracia-Fernández, C.; Lugo, L. (Solid + liquid) phase equilibria and heat capacity of (diphenyl ether + biphenyl) mixtures used as thermal energy storage materials. J. Chem. Thermodyn. 2014, 74, 43-50. [CrossRef]

86. Halelfadl, S.; Estellé, P.; Aladag, B.; Doner, N.; Maré, T. Viscosity of carbon nanotubes water-based nanofluids: Influence of concentration and temperature. Int. J. Therm. Sci. 2013, 71, 111-117. [CrossRef]

87. Pierre, A.; Lanos, C.; Estellé, P. Extension of spread-slump formulae for yield stress evaluation. Appl. Rheol. 2013, 23, 1-9.

88. ASTM International. ASTM D7896-14 Standard Test Method for Thermal Conductivity, Thermal Diffusivity and Volumetric Heat Capacity of Engine Coolants and Related Fluids by Transient Hot Wire Liquid Thermal Conductivity Method; ASTM International: West Conshohocken, PA, USA, 2014.

89. Banisharif, A.; Aghajani, M.; Van Vaerenbergh, S.; Estellé, P.; Rashidi, A. Thermophysical properties of water ethylene glycol (WEG) mixture-based $\mathrm{Fe}_{3} \mathrm{O}_{4}$ nanofluids at low concentration and temperature. J. Mol. Liq. 2020, 302, 112606. [CrossRef]

90. Zeroual, S.; Estellé, P.; Cabaleiro, D.; Vigolo, B.; Emo, M.; Halim, W.; Ouaskit, S. Ethylene glycol based silver nanoparticles synthesized by polyol process: Characterization and thermophysical profile. J. Mol. Liq. 2020, 310, 113229. [CrossRef]

91. Lemmon, E.W.; Huber, M.L.; McLinden, M.O. NIST Standard Reference Database 23: Reference Fluid Thermodynamic and Transport Properties (REFPROP), Version 9.0. Physical and Chemical Properties; NIST: Gaithersburg, MD, USA, 2010.

92. Żyła, G.; Vallejo, J.P.; Fal, J.; Lugo, L. Nanodiamonds-Ethylene glycol nanofluids: Experimental investigation of fundamental physical properties. Int. J. Heat Mass Transf. 2018, 121, 1201-1213. [CrossRef]

93. Wanic, M.; Cabaleiro, D.; Hamze, S.; Fal, J.; Estellé, P.; Żyła, G. Surface tension of ethylene glycol-based nanofluids containing various types of nitrides: An experimental study. J. Therm. Anal. Calorim. 2020, 139, 799-806. [CrossRef] 
94. Gómez-Villarejo, R.; Aguilar, T.; Hamze, S.; Estellé, P.; Navas, J. Experimental analysis of water-based nanofluids using boron nitride nanotubes with improved thermal properties. J. Mol. Liq. 2019, 277, 93-103. [CrossRef]

95. Żyła, G.; Fal, J.; Estellé, P. Thermophysical and dielectric profiles of ethylene glycol based titanium nitride (TiN-EG) nanofluids with various size of particles. Int. J. Heat Mass Transf. 2017, 113, 1189-1199. [CrossRef]

96. Wang, F.; Zhang, P.; Mou, Y.; Kang, M.; Liu, M.; Song, L.; Lu, A.; Rong, J. Synthesis of the polyethylene glycol solid-solid phase change materials with a functionalized graphene oxide for thermal energy storage. Polym. Test. 2017, 63, 494-504. [CrossRef]

97. Pielichowski, K.; Flejtuch, K. Differential scanning calorimetry studies on poly(ethylene glycol) with different molecular weights for thermal energy storage materials. Polym. Adv. Technol. 2002, 13, 690-696. [CrossRef]

98. Lai, W.C.; Hsueh, C.Y.; Chang, C.W. Nanostructured polymers with embedded self-assembled networks: Reversibly tunable phase behaviors and physical properties. Soft Matter 2019, 15, 6427-6435. [CrossRef] [PubMed]

99. Meng, Q.; Hu, J. A poly(ethylene glycol)-based smart phase change material. Sol. Energy Mater. Sol. Cells 2008, 92, 1260-1268. [CrossRef]

100. Meyer, A.R.; Bender, C.R.; Dos Santos, D.M.; Ziembowicz, F.I.; Frizzo, C.P.; Villetti, M.A.; Reichert, J.M.; Zanatta, N.; Bonacorso, H.G.; Martins, M.A.P. Effect of slight structural changes on the gelation properties of N-phenylstearamide supramolecular gels. Soft Matter 2018, 14, 6716-6727. [CrossRef] [PubMed]

101. Pereiro, A.B.; Pastoriza-Gallego, M.J.; Shimizu, K.; Marrucho, I.M.; Lopes, J.N.C.; Piñeiro, M.M.; Rebelo, L.P.N. On the formation of a third, nanostructured domain in ionic liquids. J. Phys. Chem. B 2013, 117, 10826-10833. [CrossRef] [PubMed]

102. Hermida-Merino, C.; Pérez-Rodríguez, M.; Piñeiro, M.M.; Pastoriza-Gallego, M.J. Evidence of viscoplastic behavior of exfoliated graphite nanofluids. Soft Matter 2016, 12, 2264-2275. [CrossRef] [PubMed]

103. Cabaleiro, D.; Pastoriza-Gallego, M.J.; Gracia-Fernández, C.; Piñeiro, M.M.; Lugo, L. Rheological and volumetric properties of $\mathrm{TiO}_{2}$ - ethylene glycol nanofluids. Nanoscale Res. Lett. 2013, 8, 286. [CrossRef] [PubMed]

104. Vogel, H. The law of the relation between the viscosity of liquids and the temperature. Phys. Z. 1921, 22, 645-646.

105. Fulcher, G.S. Analysis of recent measurements of the viscosity of glasses. J. Am. Ceram. Soc. 1925, 8, 339-355. [CrossRef]

106. Tammann, G.; Hesse, W. The dependence of viscosity upon the temperature of supercooled liquids. Z. Anorg. Allg. Chem. 1926, 156, 245-257. [CrossRef]

107. Sillick, M.; Gregson, C.M. Viscous fragility of concentrated maltopolymer/sucrose mixtures. Carbohydr. Polym. 2009, 78, 879-887. [CrossRef]

108. Afzal, W.; Mohammadi, A.H.; Richon, D. Volumetric properties of mono-, di-, tri-, and polyethylene glycol aqueous solutions from (273.15 to 363.15) K: Experimental measurements and correlations. J. Chem. Eng. Data 2009, 54, 1254-1261. [CrossRef]

109. Trivedi, S.; Pandey, S. Densities of 1-Butyl-3-methylimidazolium hexafluorophosphate poly(ethylene glycol) in the temperature range (283.15 to 363.15) K. J. Chem. Eng. Data 2011, 56, 2168-2174. [CrossRef]

110. Niu, Y.; Gao, F.; Zhu, R.; Sun, S.; Wei, X. Solubility of dilute $\mathrm{SO}_{2}$ in mixtures of $\mathrm{N}, \mathrm{N}$-dimethylformamide + polyethylene glycol 400 and the density and viscosity of the mixtures. J. Chem. Eng. Data 2013, 58, 639-647. [CrossRef]

111. Sani, E.; Vallejo, J.P.; Cabaleiro, D.; Lugo, L. Functionalized graphene nanoplatelet-nanofluids for solar thermal collectors. Sol. Energy Mater. Sol. Cells 2018, 185, 205-209. [CrossRef]

112. Cabaleiro, D.; Colla, L.; Barison, S.; Lugo, L.; Fedele, L.; Bobbo, S. Heat transfer capability of (ethylene glycol + water)-based nanofluids containing graphene nanoplatelets: Design and thermophysical profile. Nanoscale Res. Lett. 2017, 12, 53. [CrossRef] [PubMed]

113. Nayak, A.K.; Singh, R.K.; Kulkarni, P.P. Thermal expansion characteristics of $\mathrm{Al}_{2} \mathrm{O}_{3}$ nanofluids: More to understand than understood. Appl. Phys. Lett. 2009, 94, 094102. [CrossRef]

114. Fu, D.; Du, L.; Wang, H. Experiment and model for the surface tension of MEA-PEG400 and DEA-PEG400 aqueous solutions. J. Chem. Thermodyn. 2014, 69, 132-136. [CrossRef]

(C) 2020 by the authors. Licensee MDPI, Basel, Switzerland. This article is an open access article distributed under the terms and conditions of the Creative Commons Attribution (CC BY) license (http://creativecommons.org/licenses/by/4.0/). 